\title{
Robust Measures of Core Inflation for Vietnam
}




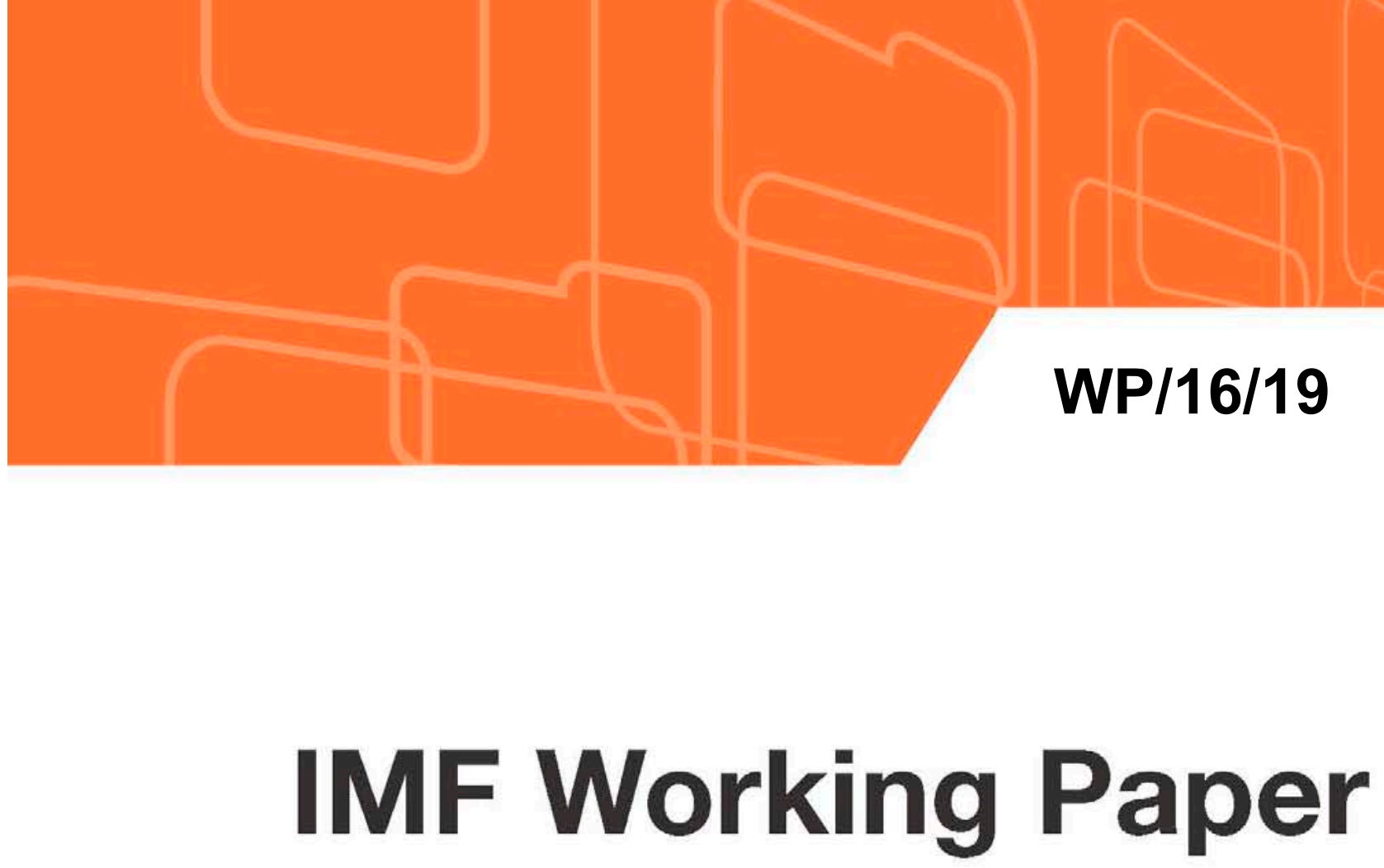

\section{Robust Measures of Core Inflation for Vietnam}

Sanjay Kalra and Bui Thi Trang Dzung

IMF Working Papers describe research in progress by the author(s) and are published to elicit comments and to encourage debate. The views expressed in IMF Working Papers are those of the author(s) and do not necessarily represent the views of the IMF, its Executive Board, or IMF management. 


\title{
IMF Working Paper
}

Secretary's Department

\section{Robust Measures of Core Inflation for Vietnam \\ Prepared by Sanjay Kalra and Bui Thi Trang Dzung ${ }^{1}$}

Authorized for distribution by Thomas Rumbaugh

February 2016

\begin{abstract}
IMF Working Papers describe research in progress by the author(s) and are published to elicit comments and to encourage debate. The views expressed in IMF Working Papers are those of the author(s) and do not necessarily represent the views of the IMF, its Executive Board, or IMF management.
\end{abstract}

\begin{abstract}
The paper develops robust measures of core inflation for Vietnam that can be used in policy making. These core inflation measures (CIMs) are based on an analytical evaluation of the inflation process in Vietnam, and use a filtering approach to narrow down potential measures that satisfy certain empirically desirable criteria. The paper finds that commonly used exclusion-based measures (EBMs) do not perform well against these empirical criteria; trimmed mean measures (TMMs) do better. Among TMMs, "one trim does not fit all periods"; periods of high and variable inflation require larger trims, and conversely. EVIEWS and MATLAB programs which accompany the paper allow quick, timely replication of CIMs as new data become available, making them valuable tools for the State Bank of Vietnam on an ongoing basis.

JEL Classification Numbers: C13, E31, E52

Keywords: Core inflation, Monetary Policy; Vietnam

Author's E-Mail Address:skalra@imf.org; buitrangdung@gmail.com

\footnotetext{
${ }^{1}$ International Monetary Fund and State Bank of Vietnam, respectively.

${ }^{2}$ This paper was prepared at the IMF Resident Representative Office in Hanoi. The authors are grateful to the State Bank of Vietnam for granting permission to Ms. Dzung to work as an intern in the Res Rep Office, and to the General Statistics Office of the Ministry of Planning and Investment for providing the data. The authors are especially grateful to Deputy Governor Hong, Director General Hoai Anh (ICD), Director General Quoc Dzung (FSD), and Deputy Director General An (ICD) for their support for this project. The authors also thank John Nelmes and Jochen Schmittmann for helpful comments.
} 


\section{Contents}

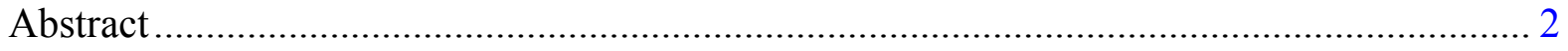

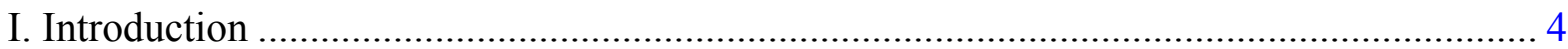

II. The Inflation Process in Vietnam—Key Elements .............................................. 5

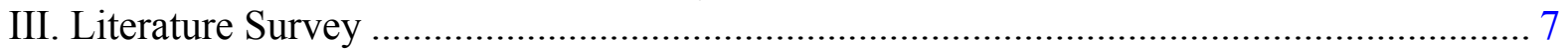

A. Core Inflation - Conceptual Issues ................................................................ 7

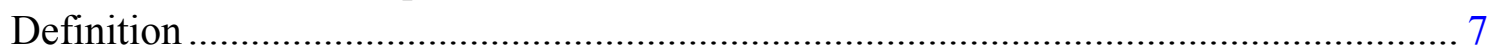

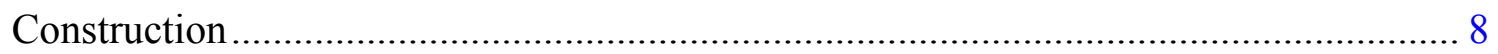

B. Empirical Literature on Core Inflation Measures for Vietnam ................................... 9

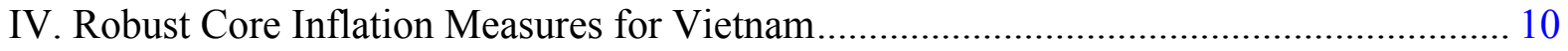

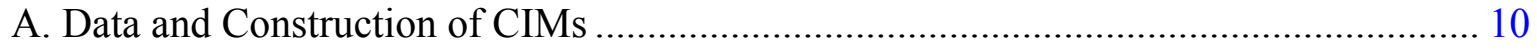

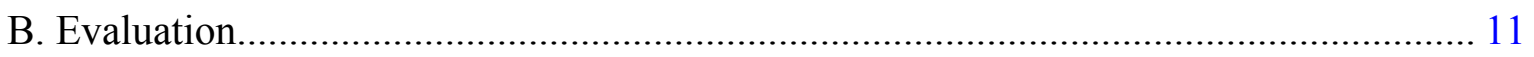

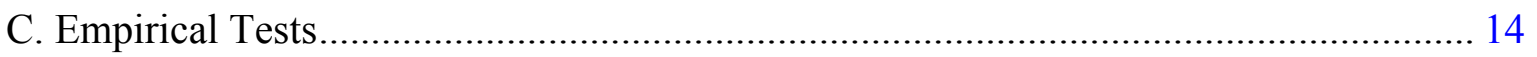

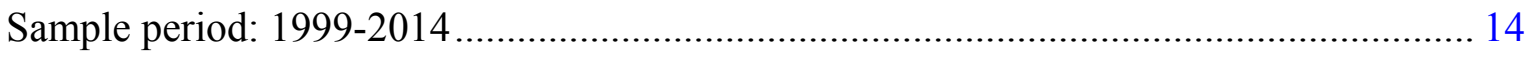

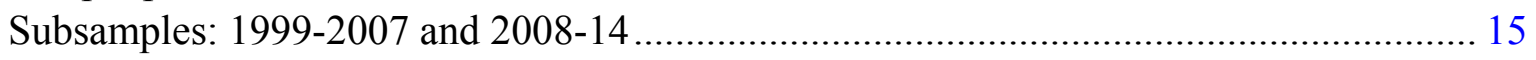

Cogley tests and Reversion Horizons.................................................................... 15

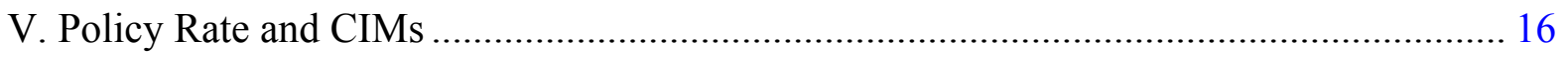

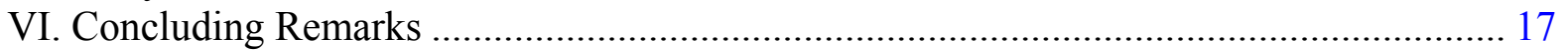

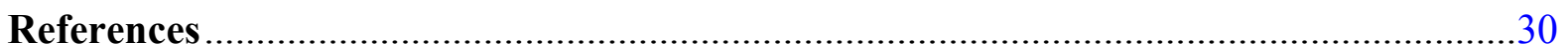

\section{Tables}

Table 1. Headline Inflation: Cross-Country Comparison ............................................... 6

Table 2. Cross-Country Practices: Exclusion-based CIMs............................................... 8

Table 3. Exclusion-based CIMs: Definitions and Excluded Weights................................. 11

Table 4. Evaluation of Exclusion-based CIMs (12-month) —Sample: 1999-2014............... 18

Table 5. Evaluation of Exclusion-based CIMs (12-month)—Sample: 1999-2007................ 21

Table 6. Evaluation of Exclusion-based CIMs (12-month)—Sample: 2008-2014............... 24

Table 7. Cogley Test Wald F-statistics ..................................................................... 28

\section{Figures}

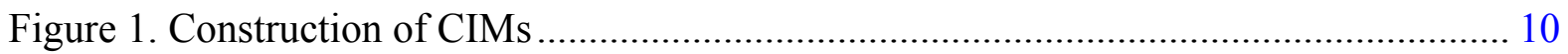

Figure 2. Evaluation Process for CIMs .................................................................... 12

Figure 3. 12-month TMMs: Marques et. al. "Attractor" Conditions_-Sample: 1999-2014... 19

Figure 4. 12-month TMMs: Smoothness and Volatility-Sample: 1999-2014 .................. 20

Figure 5. 12-month TMMs: Marques et. al. “Attractor” Conditions-Sample: 1999-2007... 22

Figure 6. 12-month TMMs: Smoothness and Volatility-Sample: 1999-2007 ................... 23

Figure 7. 12-month TMMs: Marques et. al. "Attractor” Conditions-Sample: 2008-2014... 25

Figure 8. 12-month TMMs: Smoothness and Volatility—Sample: 2008-2014 .................. 26

Figure 9. Cogley Tests for TMM $\beta$ s ............................................................................ 27

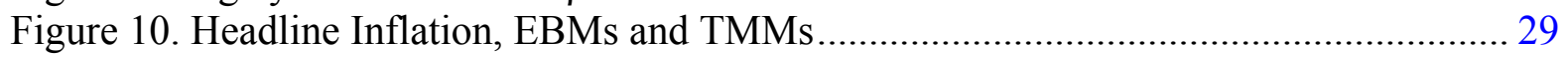




\section{INTRODUCTION}

Over the course of the last decade, the State Bank of Vietnam responded to high inflation episodes in 2008 and 2011 by raising policy rates. Was this response warranted, or warranted to the extent that it was undertaken? Contrarian as this question may appear, there are valid reasons - theoretical and practical - to ask this question. First, a substantive part of the headline inflation in both episodes was associated with global rice and oil price movements. Also, headline inflation rose and fell quickly over 6-8 months suggesting that, as a first approximation, these changes may have been more in the nature of temporary, external supply shocks than persistent, domestic demand shocks. Were underlying inflation pressures more muted? Second, the increases in the policy rates, and thereby those in the deposit and lending rates in the banking system, lagged headline inflation and generated large swings in the real interest rate. The large increases substantially raised the funding costs of enterprises and impacted the balance sheets of financial institutions. Should the central bank have responded less to headline inflation and more to underlying inflation pressures? In the future, what forwardlooking, underlying measure of inflation could the State Bank of Vietnam (SBV) focus on as
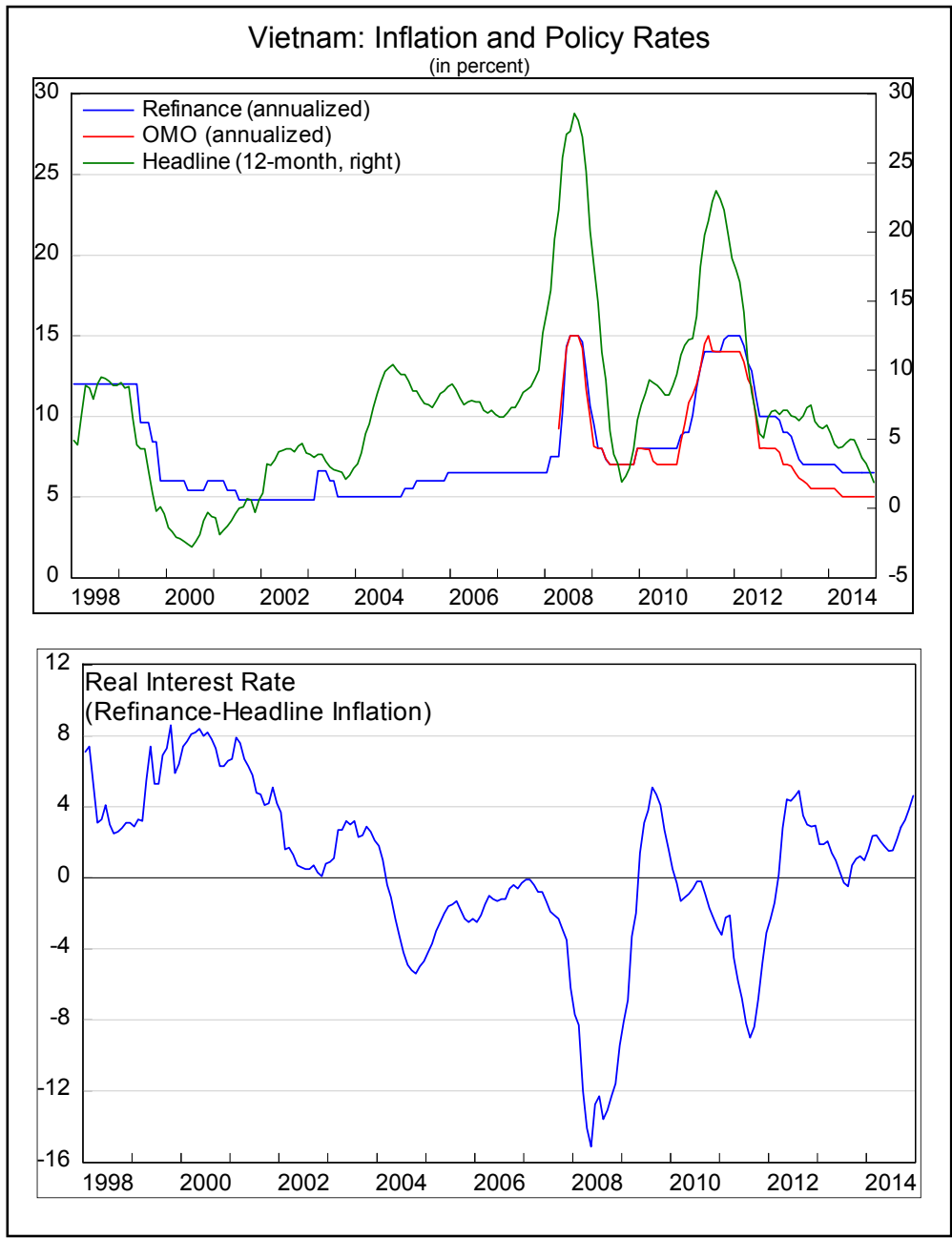
guide to policy making?

This paper addresses these analytical and policy issues. The main element of this paper is to construct and evaluate alternative measures of core inflation. The remainder of this paper is organized as follows. Section II provides an overview of the inflation process in Vietnam over a longer time horizon to extract the key determinants of inflation. Section III has a selected literature survey, including definitions and construction of core inflation measures (CIM). This section also refers to the limited empirical literature on core inflation measures for Vietnam. Section IV constructs and evaluates core inflation measures for Vietnam. 
Section $\mathrm{V}$ offers concluding remarks and recommendations. As part of these recommendations, the paper identifies CIMs that the State Bank of Vietnam could use for internal analytical and policy making purposes and others that may be better suited for external communications. Over the longer term, reliable CIMs could form the basic foundation of a shift to an inflation targeting regime in Vietnam.

\section{The Inflation Process In VietnaM-Key Elements}

Vietnam experienced high and variable inflation over the last three decades. Several factors-domestic and external — played a role in shaping the inflation dynamics.

After the failure of the 1985 reform package, hyperinflation ensued and 12-month headline inflation peaked at 775 percent at end-1986. ${ }^{3}$

With doi moi in 1986, and several measures including higher interest rates, cuts in subsidies to SOEs, significant moderation of wage increases, and cuts in budget expenditure/deficits, inflation was brought down to two-digit level, and then fell to the single-digit territory for the first time in 1993. Inflation stayed at high levels in the intervening
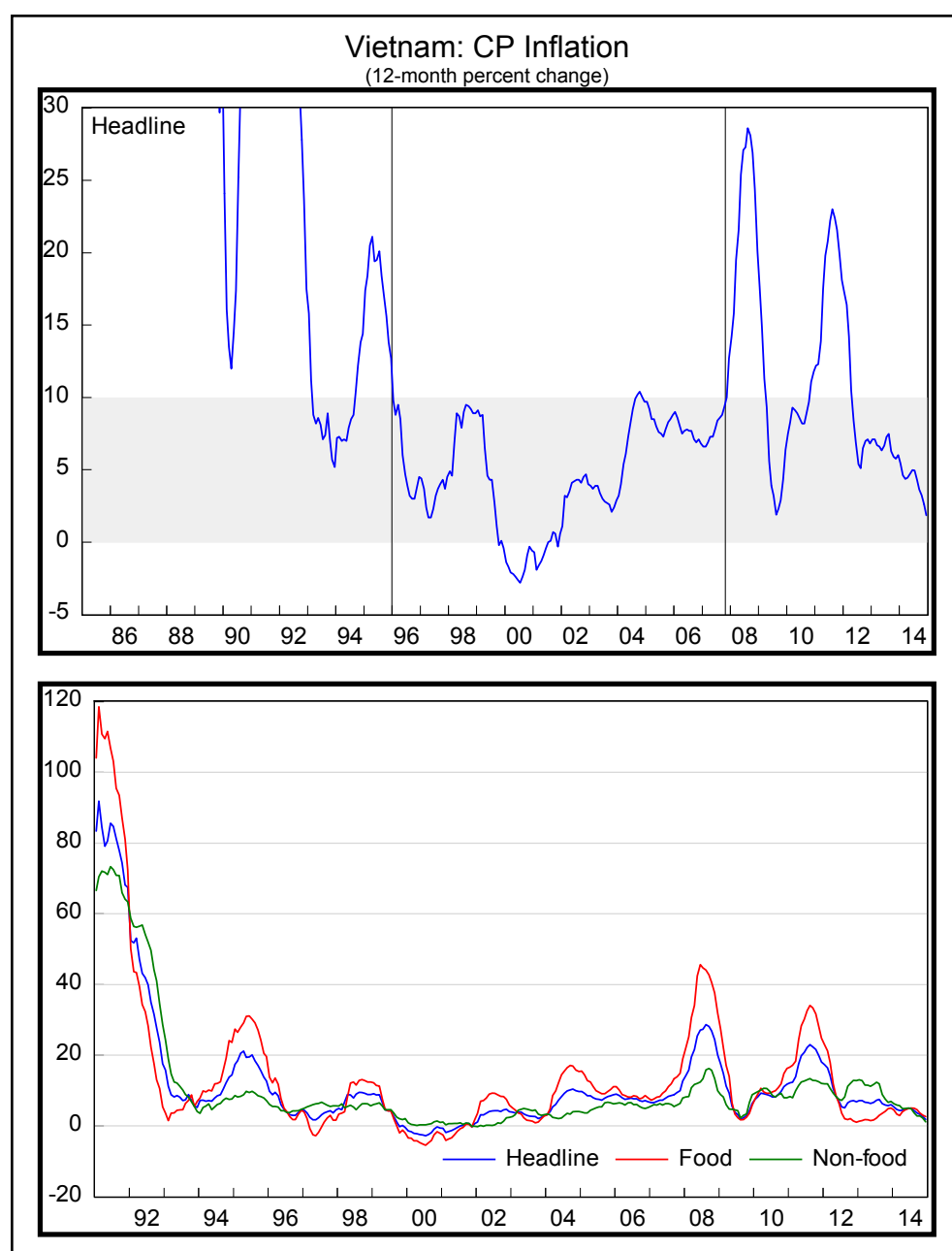
period.

Inflation stayed in the single digits for over a decade during 1996-2007.

Under pressures from rapid growth, droughts, avian flu, and a combination of loose macroeconomic policies domestically and external shocks, inflation rose rapidly again in 2007, peaking at $281 / 2$ percent $y / y$ in August 2008. It then fell quickly to single-digit levels six months later as global rice and oil prices fell.

\footnotetext{
${ }^{3}$ The package was called "Adjustment of Price, Wage and Money" (see Nguyen, Cavoli and Wilson, 2012).
} 
Component Inflation: Skewness and Kurtosis
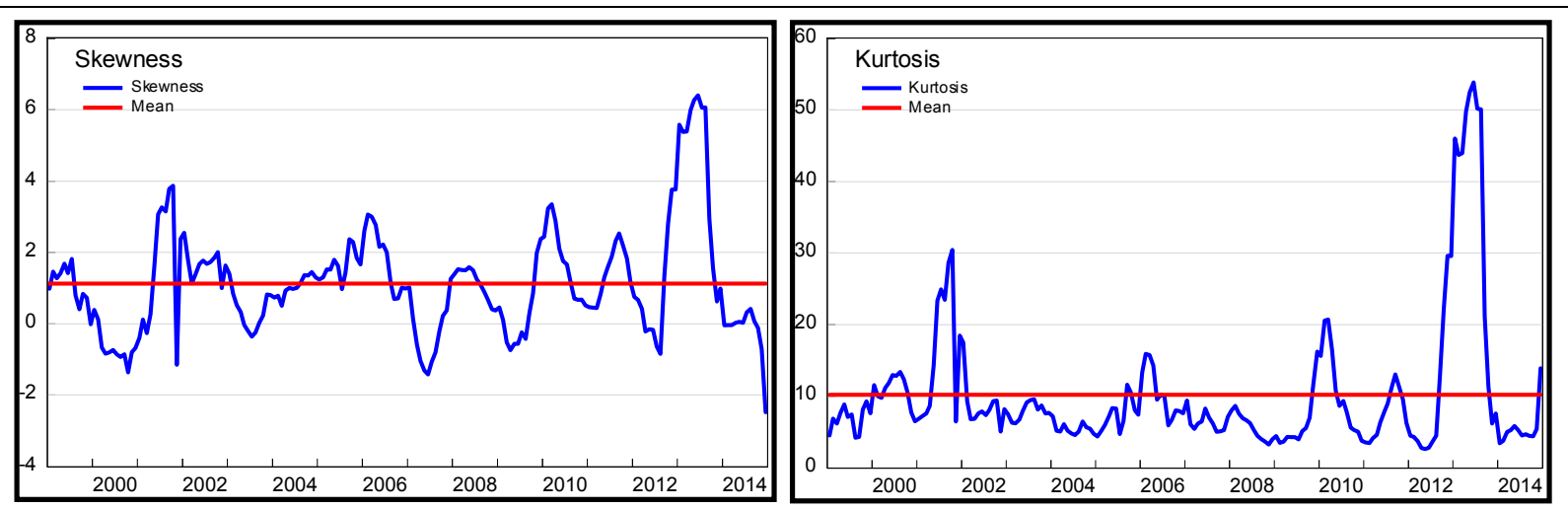

\section{LITERATURE SURVEY}

\section{A. Core Inflation-Conceptual Issues}

\section{Definition}

The extensive theoretical literature on core inflation does not provide a unique definition of core inflation. Okun (1970) views core inflation as “... a condition of generally rising prices", Flemming (1976) as “... the rate at which the general level of prices in [the] economy is changing", and Eckstein (1981) as "... the trend increase of the cost of the factors of production". Quah and Vahey (1995) define core inflation as a "... component of measured inflation that has no medium- to long-term impact on real output". Roger (1998) divides the various definitions into two views of core inflation: persistent and generalized. Silver (2006) provides an overview of statistical measurement issues relating to alternative measures of core inflation. The approaches to measurement include exclusion-based methods, imputation methods, limited influence estimators, reweighting, and economic modeling.

To fix notation, consider the CPI index $P_{t}$ in period $t$ as the weighted sum of $n$ individual component series $P_{i t}$ where the weights $\alpha_{i}$ sum to 1 . Then inflation $\pi_{\tau}$ is a weighted sum the component inflations $\pi_{i t}$ with time varying weights.

$$
\begin{aligned}
& P_{t}=\sum_{i=1}^{n} \alpha_{i} P_{i t} ; \sum_{i=1}^{n} \alpha_{i}=1 \\
& \pi_{t}=\sum_{i=1}^{n} \omega_{i t} \pi_{i t} ; \sum_{i=1}^{n} \omega_{i t}=1
\end{aligned}
$$

Component inflation can be understood as being driven by two parts: core inflation $\left(\pi_{t}^{*}\right)$ and commodity-specific shocks $\left(v_{i t}\right)$. Headline inflation is the sum of core inflation $\left(\pi_{t}^{*}\right)$ and an error term $u_{t}$. Under specific assumptions on $v_{i t}, u_{t}$ is normal, mean zero and stationary.

$$
\begin{aligned}
& \pi_{i t}=\pi_{t}^{*}+v_{i t} \\
& \pi_{t}=\pi_{t}^{*}+u_{t} ; u_{t} \sim \text { Normal, mean zero, stationary }
\end{aligned}
$$




\section{Construction}

Examples of core inflation as the persistent component of inflation include filtering or smoothing techniques which equate core inflation with the trend component, or use a univariate regression model. Core inflation as generalized inflation consists of two main methodologies: exclusion-based measures (EBMs) and limited influence measures (LIMs).

EBMs are by far the most commonly used by central banks, given ease of computation, timeliness, replicability, and transparency. A popular measure is the CPI excluding components like food (because of weather conditions, inter alia) and energy (considered volatile and subject to supply shocks or seasonality). Administered prices, indirect taxes, interest (mortgage) payment are also often excluded as they are erratic and endogenous to policy making. In the computation of EBMs, weights of excluded items are reduced to zero, and the weights of the remaining included items are increased proportionately (to sum up to 1). Continuing with the notation as above, an EBM of core inflation which excludes food and energy would be: ${ }^{4}$

$$
\pi_{t}^{*}=\sum_{i=3}^{n} \tilde{\omega}_{i t} \pi_{i t} \text {, where } \omega_{i t}=0 \text { for food (1) and energy (2) and } \sum_{i=3}^{n} \tilde{\omega}_{i t}=1
$$

However, exclusion should be done with caution. It is important to distinguish between signal and noise in the inflation data. For example, given food often account for a large portion of CPI basket, exclusion of the whole group may lead to the loss not only of noise, but also a substantial part of the signal. Hence, exclusion of a narrower group such as raw food may be more appropriate, especially if it is the main source of volatility.

Table 2. Cross-Country Practices: Exclusion-based CIMs

\begin{tabular}{|ll|}
\hline Excluded components & \multicolumn{1}{c|}{ Country } \\
\hline 1. Food and Energy & $\begin{array}{l}\text { Thailand, Korea, Canada, USA, Norway (Energy), Japan } \\
\text { (Food), Spain and Portugal (Energy and Food), the } \\
\text { Netherlands (fruits, vegetables and energy) }\end{array}$ \\
& $\begin{array}{l}\text { Czech Republic, Norway, Canada } \\
\text { 2. Indirect taxes }\end{array}$ \\
$\begin{array}{ll}\text { 3. Administered prices } \\
\text { 4. Interest, interest rate mortgage loan, housing rental }\end{array}$ \\
$\begin{array}{ll}\text { Sources: National authorities. } \\
\text { UK, Australia, New Zealand, Ireland, South Africa }\end{array}$ \\
\hline
\end{tabular}

LIMs (or stochastic estimators) are measures that exclude a specific proportion at the tail of the distribution of price changes in the components of the CPI basket. The set of "trimmed" items changes each month, depending on which items show extreme price movement. The most common LIMs are weighted median and trimmed means. The weighted median is the value of the middle price change when price changes are ranked based on expenditure shares.

\footnotetext{
${ }^{4}$ Several studies suggest exclusion/adjustment for the impact of other policies, such as changes in indirect taxes, on the CPI index in constructing CIMs. However, these issues are not easy to tackle empirically. Equally, others such as Wynne (2008) argue that it might be better not to make these adjustments if the objective is to capture the "true cost-of-living".
} 
Trimmed (symmetric) means omit predetermined upper and lower tails of the distribution of price changes. For example, a CPI1010 would exclude 10 percent of the weight at the top and bottom of a (ranked) distribution of price changes. The weighted median is an extreme type of trimmed symmetric mean. In notation, trimmed mean CIMs take the form:

$$
\pi_{t}^{*}=\sum_{i=j}^{n-k} \tilde{\omega}_{i t} \pi_{i t} \text {, where } \omega_{i}=0 \text { for } i<j \text { and } i>k ; \pi_{1 t}<\pi_{2 t}<\ldots<\pi_{j t}<\ldots<\pi_{k t}<\ldots<\pi_{n t} \text { and } \sum_{i=j}^{n-k} \tilde{\omega}_{i t}=1
$$

An advantage of LIMs includes robustness to price shocks. Moreover, inflationary trends relative to "noise" are broadly well captured by these measures. However, the distribution of CPI component price changes is often non-normal — usually skewed to the right and leptokurtic. This requires the construction of asymmetrically trimmed means which shave off a large/smaller percent of the CPI basket at the upper/lower end of the distribution of price changes. The rationale for this comes from a view that each price change in a component of the CPI basket consists of trend inflation and an idiosyncratic relative price shock. If the distribution of relative price shock is normal, then the weighted average based CPI would be a reasonably good estimator of trend inflation.

These CIMs are not without problems. They are harder to communicate to the public. Moreover, transitory shocks are not always separated from persistent shocks, so that noise and signal may again be mixed up. In addition, these measures are relatively sensitive to the level of aggregation of data selected, and the length of time series over which price changes are taken (Khatri and Roger, 2007).

\section{B. Empirical Literature on Core Inflation Measures for Vietnam}

There is a limited empirical literature on CIMs for Vietnam. As part of the IMF's technical assistance program, the development of CIMs was proposed in a series of reports. These reports suggested that EBMs (especially CPIxF and CPIxFEA) could potentially serve as CIMs given their transparency and timeliness, but do not conduct formal tests for the CIMs. These reports also suggested construction of Trimmed Mean Measures (TMMs) as they were considered to be theoretically "smoother" and hence useful for policy purposes. Again, several of these properties were not empirically tested. The sample period for CIMs constructed under this initiative was January 1998 to October 2006.

Lai (2013) provides a more recent attempt to evaluate CIMs for Vietnam. It evaluates five measures of core inflation: excluding food price, trimmed-mean, weighted median, exponentially smoothed and output-neutral inflation. These CIMs are evaluated empirically for tracking the trend, predictive power and cointegration with headline inflation. The key finding is that the output-neutral inflation satisfies almost all of the evaluation criteria, and could be used for analytical purposes, in conjunction with either the trimmed-mean or weighted median for communication purposes due to their relatively simple construction. The analysis in this paper uses a significantly longer sample period than Lei (2008Q12013Q1) and uses a different set of evaluation criteria. In particular, this paper uses the "attractor" conditions proposed by Marques et. al. to evaluate the alternative core inflation measures. 
Figure 1. Construction of CIMs

\section{EBMs}

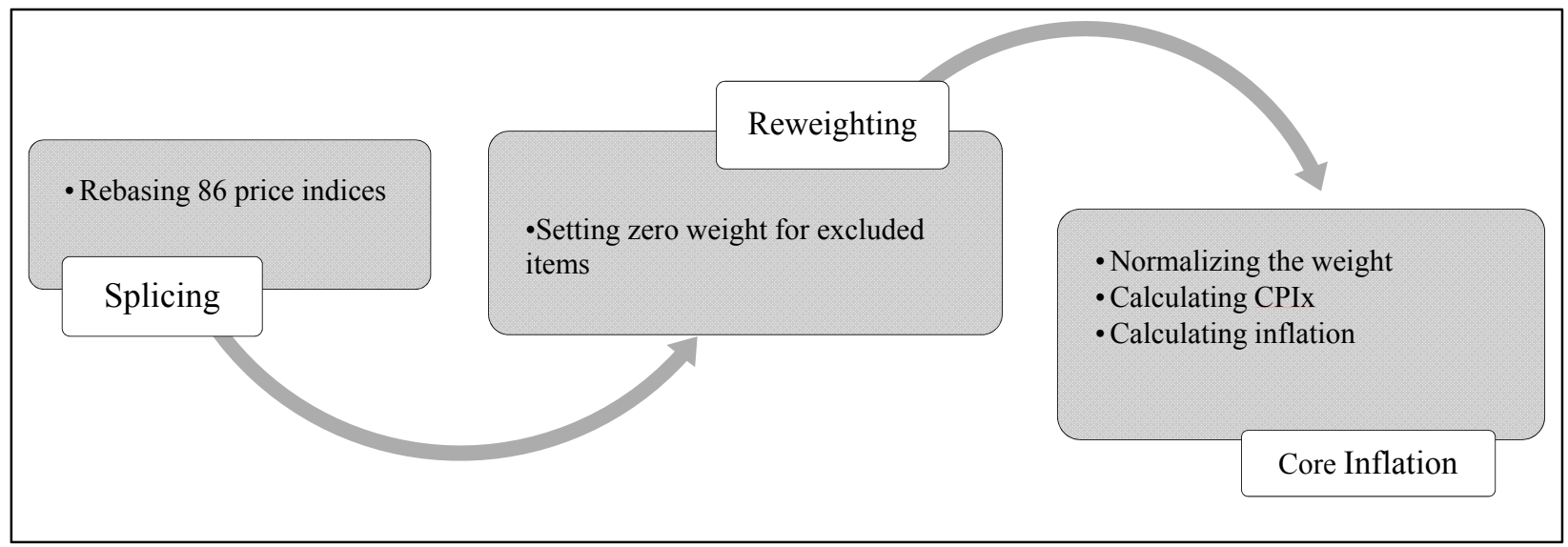

LIMs

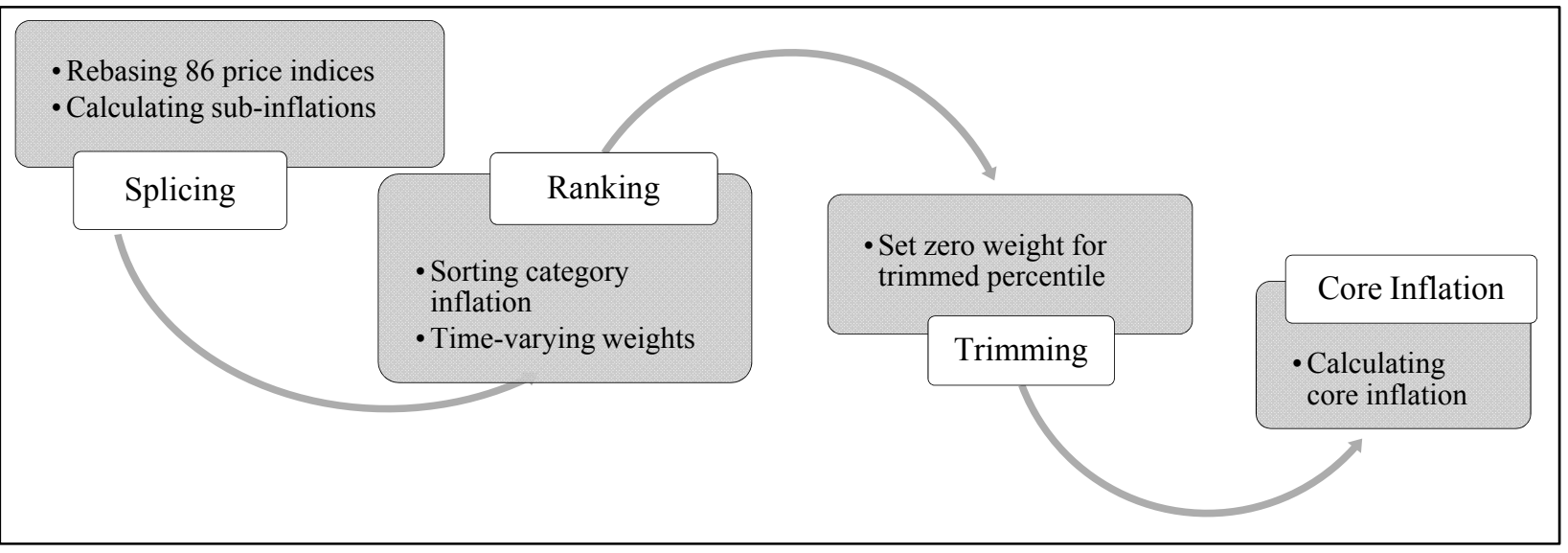

\section{Robust Core Inflation Measures for Vietnam}

\section{A. Data and Construction of CIMs}

Monthly CPI data for Vietnam is complied and announced by the General Statistics Office (GSO). We use this data to compute CIMs, both EBMs and TMMs. Since the methodology of CPI compilation in Vietnam is in accordance with international standards, the credibility and transparency of the CPI data are a good starting basis for the construction of CIMs. We first splice the four following different segments into a single headline CPI and component CPI series for the period January 1998-December $2014:^{5}$

1. Period 1: January 1998-June 2001, base year 1995, with 300 components;

2. Period 2: July 2001-April 2006, base year 2000, including 390 items;

3. Period 3: May 2006- October 2009, base year 2005, including 496 components; and

4. Period 4: November 2009-December 2014, base year 2009, with 572 items.

\footnotetext{
${ }^{5}$ The $87^{\text {th }}$ component (sewing machine) appears only in Period 1 with negligible weight and was dropped.
} 
CIMs are constructed for 12-month price changes as in Figure 1 above. The procedure can similarly be applied for other horizons. The full sample period is January 1999-December 2014. Table 3 provides definitions and excluded weights for eight EBMs analyzed in this paper. Of these, two measures - CPIxF and CPIxFEA - were recommended by the SBVGSO Inter-ministerial Working Group on Core Inflation based on IMF technical assistance. Later, Health Care Services and Education Services were among the excluded items groups given large changes (especially since 2010 and in 2012-13) as Vietnam moves to "marketization" of these services.

For TMMs, the breakdown of monthly CPI into 86 components at the 2-digit level was used. This is a higher level of disaggregation than has been used in any previous study. Several TMM measures - symmetric and asymmetric - were constructed with the left and right trims ranging between 15 percent and 30 percent, at 1 percent intervals, so that a total of around 225 TMMs were constructed and evaluated. The procedure was repeated for two subsamples: 1999-2007 and 2008-14.

Table 3. Exclusion-based CIMs: Definitions and Excluded Weights

\begin{tabular}{|c|c|c|c|c|}
\hline $\mathrm{CIM}$ & $\begin{array}{l}\text { 1998M1: } \\
\text { 2001M6 }\end{array}$ & $\begin{array}{l}\text { 2001M7: } \\
\text { 2006M4 }\end{array}$ & $\begin{array}{l}\text { 2006M5: } \\
\text { 2009M10 }\end{array}$ & $\begin{array}{l}\text { 2009M11: } \\
\text { 2014M12 }\end{array}$ \\
\hline $\begin{array}{l}\text { CPIxA (excludes } 4 \text { items of administered prices: water, electricity, public } \\
\text { transport services). }\end{array}$ & 2.1 & 3.2 & 5.0 & 3.7 \\
\hline $\begin{array}{l}\text { CPIXAHE (excludes } 4 \text { items of administered prices, health care services } \\
\text { and education services). }\end{array}$ & 3.9 & 6.2 & 11.6 & 12.4 \\
\hline CPIxE (excludes el ectricity, gas, and fuel). & 6.7 & 5.4 & 8.5 & 8.3 \\
\hline $\begin{array}{l}\text { CPIxF (excludes } 8 \text { items of raw food: rice, wheat cereal, fresh meat, eggs, } \\
\text { fresh seafood, vegetables, and fruits). }\end{array}$ & 43.5 & 29.6 & 26.5 & 24.1 \\
\hline CPIxFA (excludes 8 items of raw food and 4 items of administered prices). & 45.5 & 32.8 & 31.5 & 27.7 \\
\hline CPIxFE (excludes 8 items of raw food, electricity, gas, and fuel) & 50.1 & 35.0 & 35.0 & 32.3 \\
\hline $\begin{array}{l}\text { CPIxFEA (excludes } 8 \text { items of raw food, } 3 \text { items of energy, and } 4 \text { items of } \\
\text { administered prices) }\end{array}$ & 50.7 & 36.1 & 36.6 & 33.5 \\
\hline $\begin{array}{l}\text { CPIxFEAHE (excludes } 8 \text { items of raw food, } 3 \text { items of energy, } 4 \text { items of } \\
\text { administered prices, health care services, and education services) }\end{array}$ & 52.5 & 39.1 & 43.1 & 42.2 \\
\hline
\end{tabular}

Source: GSO; and authors' calculations.

\section{B. Evaluation}

Silver (2006) sets criteria for choosing among alternative CIMs. These criteria include credibility, control, deviations from a smoothed reference series, volatility, predictive ability, causality and cointegration tests, and correlation with money supply.

The empirical cross-country literature, however, does not generate a unique, preferred CIM. Silver (2006) concludes that country practice differs in how the various statistical approaches are implemented and how their appropriateness is assessed. There is little consistency in the results of cross-country studies to readily suggest guidelines on accepted methods. Moreover, 
a country may have various measures that are used for different purposes: some may be useful for analytical purposes but difficult to explain to the public; others may not be fully “accurate' for policy purposes, but may be very easy for the central bank to communicate and for the public to comprehend. Furthermore, the chosen CIM may differ depending on the policy horizon. In short, across countries there is not and for a country there may not be a clear cut "winner" which satisfies all purposes when choosing a CIM.

In the remainder of the paper, we use a three-step evaluation criterion to narrow down potential CIM choices (Figure 2). First, a CIM must satisfy certain necessary conditions as an "attractor" for headline inflation. For this we use the Marques et. al. (2003) conditions. Second, those CIMs that satisfy the "attractor" conditions are compared. For this comparison we use four criteria. The CIMs are compared for deviations from a reference series. For this comparison, we use Root Mean Square Deviation (RMSD) or Mean Absolute Deviation (MAD). A 12-month centered moving average of CPI inflation $\left(M A\left(\pi_{t}\right)\right)$ is typically used in the literature as the reference series. A CIM is generally expected to be less variable than headline inflation, but this may not necessarily be the case. We implement this comparison using standard deviation (SD) and coefficient of variation (CV) of the CIMs against that of headline inflation. Third, we examine the CIMs' ability to "forecast" headline inflation at different horizons using Cogley (2002) tests.

Figure 2. Evaluation Process for CIMs

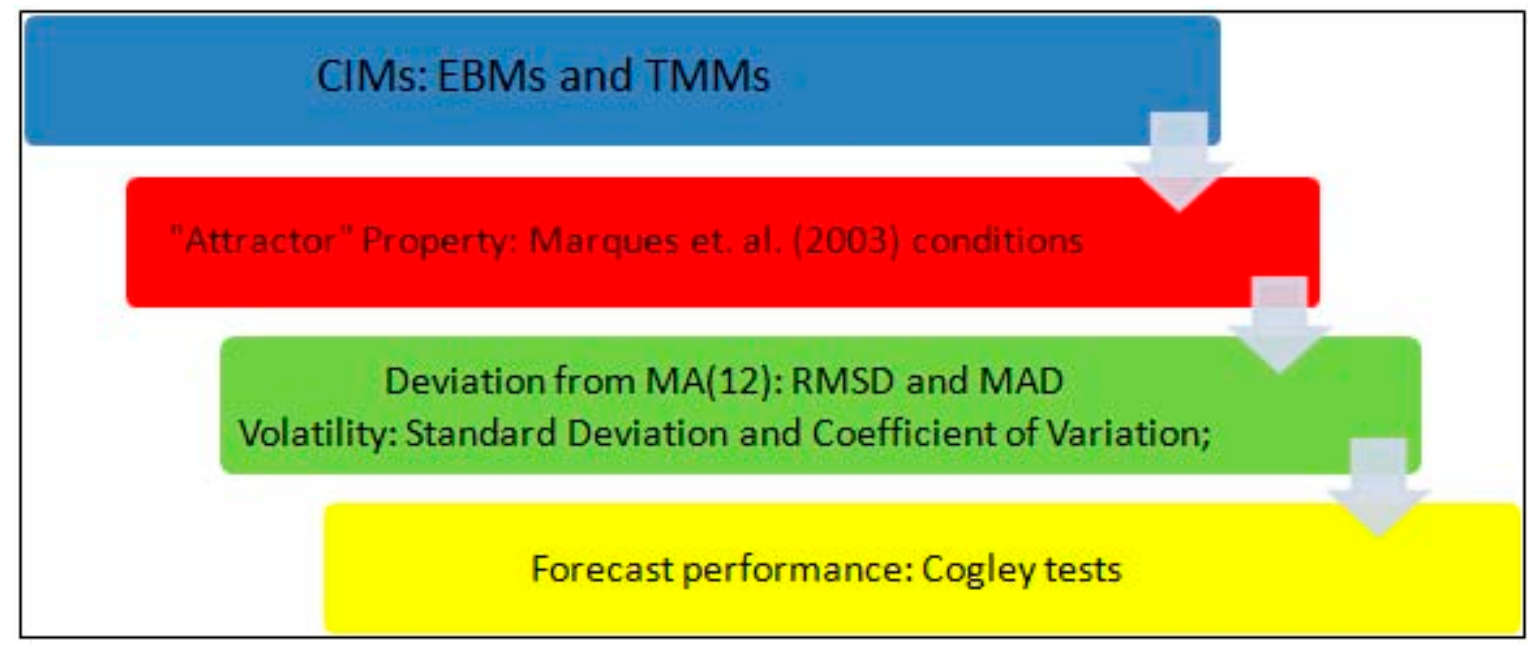

\section{Marques et. al. “Attractor” Conditions}

Marques et. al. (2003) introduces three testable, empirical conditions for evaluating CIMs:

Condition 1: Headline inflation and a CIM should not exhibit systematically divergent trends. This can be tested with the following two conditions: 
Condition 1a. Headline inflation and core inflation should be cointegrated with unit coefficient, that is, $u_{t}$ should be stationary with zero mean. ${ }^{6}$ This condition essentially means that $\pi_{t}$ and $\pi_{t}^{*}$ cannot exhibit a systematically nonvanishing difference in the long run. If $u_{t}$ does not have zero mean, then $\pi_{t}^{*}$ does not capture the persistent component of inflation. This condition is one of the alternative tests for unbiasedness proposed in the literature (see Roger (2008)).

Condition 1b. Even if $u_{t}=\left(\pi_{t}-\beta \pi_{t}^{*}\right)$ is stationary but $\beta \neq 1$, headline inflation and the CIM tend to drift apart. One way to examine this property is by testing the hypothesis $\beta=1$ given $\alpha=0$ in equation (1).

$$
\left(\pi_{t}-\pi_{t}^{*}\right)=\alpha+(1-\beta) \pi_{t}^{*}+\mu_{t}
$$

Condition 2: $\pi_{t}^{*}$ is an attractor of $\pi_{t}$. This formalizes the assumption that headline inflation converges to core inflation in the long run. This condition can be tested using equation (2):

$$
\Delta \pi_{t}=\sum_{j=1}^{m} \phi_{j} \Delta \pi_{t-j}+\sum_{j=1}^{n} \xi_{j} \Delta \pi_{t-j}^{*}-\gamma\left(\pi_{t-1}-\pi_{t-1}^{*}\right)+\varepsilon_{t}
$$

This requires the existence of an error correction representation for $\pi_{t}$ which is satisfied if the null hypothesis $(\gamma=0)$ is not accepted. The implication of this condition is that headline inflation may diverge from core inflation in the short run, but is "attracted back" in the long run.

Condition 3: $\pi_{t}$ should not be an attractor of $\pi_{t}^{*}$. This condition ensures Condition 2 does not occur the other way around which can be evaluated by using the ECM for $\pi_{t}^{*}$.

$$
\Delta \pi_{t}^{*}=\sum_{j=1}^{r} \delta_{j} \Delta \pi_{t-j}^{*}+\sum_{j=1}^{s} \theta_{j} \Delta \pi_{t-j}-\lambda\left(\pi_{t-1}-\pi_{t-1}^{*}\right)+\eta_{t}
$$

Condition 3a. Weak exogeneity of the CIM requires $(\lambda=0)$.

Condition 3b. Strong exogeneity of the CIM requires $\left(\theta_{1}=\theta_{2}=\ldots=\theta_{s}=0\right)$ given $\lambda=0$.

If Condition 3 is satisfied, then changes in CIM can simply be written as an autoregressive process:

$$
\Delta \pi_{t}^{*}=\sum_{j=1}^{r} \delta_{j} \Delta \pi_{t-j}^{*}+\eta_{t}
$$

\footnotetext{
${ }^{6}$ Assuming headline inflation and CIM are I(1).
} 


\section{Cogley Tests}

Cogley (2002) proposes comparing across CIMs by investigating their predictive power for subsequent changes in inflation. It tests the relationship between the current "core deviation" $\left(\pi_{t}-\pi_{t}^{*}\right)$ with subsequent inflation changes $\left(\pi_{t+H}-\pi_{t}\right)$ using (5):

$$
\pi_{t+H}-\pi_{t}=\alpha_{H}+\beta_{H}\left(\pi_{t}-\pi_{t}^{*}\right)+\zeta_{t+H}
$$

The tested hypothesis is $\left(\alpha_{H}=0\right.$ and $\left.\beta_{H}=-1\right)$. While $\left(\alpha_{H}=0\right)$ implies that core deviations and subsequent inflation changes are mean zeros (for sufficiently large $H$, the restriction $\left(\beta_{H}=-1\right)$ means a one-for-one "correction" in future headline inflation if it moves away from its underlying level. Since the core deviation at time $t$ is considered as current transient component, any negative $\beta_{H}$ larger/smaller than 1 in absolute value could "understate"/"overstate" the magnitude of the current transients. The $R^{2}$ of (5) provides information about the goodness-of-fit of model of in which current transients help to forecast subsequent inflation. Cogley also checks for robustness by combining several CIMs and integrating macroeconomic variables in (5).

\section{Empirical Tests}

We first examine CIMs for 12-month inflation over the full sample period 1999-2014. In turn, we look at EBMs and then TMMs. Following this evaluations, we break the sample period into two subsamples: 1999-2007 and 2008-2014. The two subsamples differ noticeably in that inflation was low and less variable in the first; the second subsample saw two bouts of high inflation and inflation was also more volatile during this latter period.

\section{Sample period: 1999-2014}

\section{$E B M s$}

The evaluation of the EBMs is reported in Table 4 and has several notable features. First, none of the EBMs satisfies the Marques et. al. "attractor" conditions. Strong exogeneity is especially problematic for many of them. This is an important result as it means that, for Vietnam, the dynamics of most popularly used EBMs are affected by headline inflation, possibly through an (adaptive) expectations channel. Second, two EBMs (CPIxA and CPIxAHE) are biased. Third, two EBMs (CPIxE and CPIxAHE) are not "attractors" for CPI, although they satisfy the strong exogeneity condition. As regards variability and smoothness, not all EBMs are necessarily less variable or smoother than headline inflation. In particular, the commonly used CPIxF and CPIxFE are less variable but also less smooth (relative to $\left.M A\left(\pi_{t}\right)\right)$ than $\pi_{t}$.

TMMs

Figure 3 captures the test results of the Marques et. al. conditions for TMMs. Once again, the strong the exogeneity condition is difficult to satisfy. The attractor condition (Condition 2) 
requires trims at both the left and right tails, and large trims at the right tail reflecting the skewness of the component inflations discussed above. There is a wide range of combinations that satisfy Conditions 1 and 2, with almost all of them lying in the northeastern quadrant. Among these TMMs, only two-TMM2226 and TMM2227-satisfy all the conditions.

Figure 4 compares the smoothness and variability properties of the TMMs to that headline inflation. Again the results are rather interesting. Several of the TMMs are smoother and less variable than headline inflation, but the two TMMs that satisfy the Marques conditions are both less smooth and more variable.

\section{Subsamples: 1999-2007 and 2008-14}

Reevaluation of the CIMs over two subsamples (1998-2007 and 2008-14) provides a robustness check, but also reveals additional properties of the inflation process. Headline inflation was low in the first sample period (mean inflation and SD were $4 \frac{1}{2}$ percent and 3.9 percent, respectively); the latter sample period includes two bouts of high inflation (mean inflation and SD were 11 percent and 7.3 percent, respectively).

Once again, the EBMs fare rather poorly in satisfying the Marques conditions (Tables 5 and 6). In particular, several of them are biased or are not strongly exogenous in the first subsample; none of them satisfies the "attractor" property. The results are similar in the latter subsample, except that two EBMs-CPIxFE and CPIxFEA satisfy all conditions except unbiasedness (both have a downward bias). With a low power of the ADF test, these EBMs could potentially be considered as useful measures of core inflation, but only during periods of high inflation.

Looking at TMMs, the results are more encouraging. For the first subsample, two trims (TMM1407 and TMM1408) satisfy the Marques conditions. For the latter subsample, several trims satisfy the conditions. But there are differences among the two subsamples. The trims required in the first subsample are smaller, and larger on the left tails of the distribution. This is consistent with the lower average skewness of the component inflation in the first subsample $(0.92 ; 1.39$ in the latter subsample; 1.13 in the full sample). Given that multiple TMMs are available, further choice can be made using additional criteria. The evaluation of the TMMs with regards to the satisfaction of Marques conditions is shown in Figure 5 (for 1999-2007) and Figure 7 (for 2008-14). Indeed, the results for the full sample period are driven by the properties of the component inflation during the latter subsample. The smoothness and variability properties of the TMMs are charted in Figures 6 and 8.

\section{Cogley tests and Reversion Horizons}

Cogley tests provide additional information on the time horizons over which headline inflation reverts to CIMs (Figure 9). However, this reversion horizon is valid only if the null hypothesis of equation (5)-- $\left(\alpha_{H}=0\right.$ and $\left.\beta_{H}=-1\right)$--is satisfied. Table 7 presents the Fstatistics of the Wald test for three TMMs-TMM2226 for the full sample period; TMM147 
for the earlier sample period and TMM2119 for the latter sample period over 1-12 month horizons.

\section{Policy Rate ANd CIMs}

Several conclusions emerge from the forgoing evaluation of CIMs. First, in general, EBMs do not satisfy the postulated statistical conditions for admissible CIMs. TMMs perform better. Second, among the TMMs, admissible TMMs depend on the sample period. These sample periods, in turn, reflect the properties of the inflation process, component inflations, and the shocks that affect the inflation process. Periods with low inflation, in the case of Vietnam, are associated with less skewness and smaller outliers in the component inflations, allowing for TMMs to be constructed with smaller trims. Conversely, periods with higher, more variable inflation are associated with higher skewness in the component inflations which require larger trims to generate admissible CIMs. In short, "one trim does not fit all times".

A comparison of the admissible TMMs with a commonly used EBM (CPIxFE) is shown in Figure 10. We use the sample specific TMMs. In all cases, headline inflation traces the TMMs more closely than the EBM. The figure also provides a measure of the extent to which the EBMs under or overpredict underlying inflation pressures, on the premise that the TMMs are the "true" measures of these pressures; the under/over prediction was significant during the 2008-14 period ranging between -8 and 6 percent.

A critical aspect of the comparison between the EBM and TMMs is the speed with which underlying inflation rises and falls. The EBM suggest a slower increase and fall in core inflation than the TMMs. This has an important implication for the changes in the policy rates. The difference is especially marked in the latter subsample. Using the TMM2226, policy rates need to have been raised earlier and brought down faster than

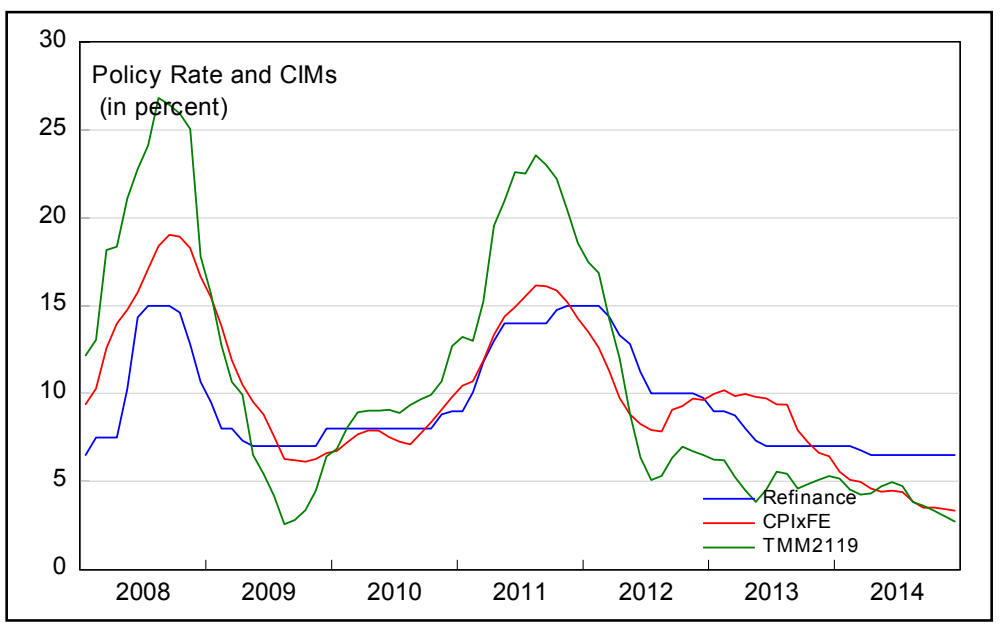
would be warranted if the EBM were to be used as a guide. The difference is noticeable in 2012 and 2013 when the SBV brought down the policy rates - justifiably - at a rapid clip, while the EBM suggested that a more cautious approach was appropriate. Indeed, during $2012 \mathrm{H} 2$ and $2013 \mathrm{H} 1$, the EBM continued to suggest that core inflation was high and in the double digits while TMM2226 suggests that core inflation had subsided markedly into the single digits. Similarly, during the earlier bout of inflation in 2008, the magnitude and speed 
with which inflation subsided appeared to have been underestimated by the EBM, as was the increase in the run up to the later bout in 2011.

\section{CONCLUDing Remarks}

Over the last half decade, the State Bank of Vietnam responded to high inflation episodes in 2008 and 2011 by raising policy rates. These policy decisions were driven, in large measure by past headline inflation, supplemented with a basic intuition of the underlying inflation pressures, past and prospective. Exclusion-based core inflation measures formed a key part of the policy decisions, although not formally stated.

This paper examines Vietnam's inflation process to over two decades to construct robust core inflation measures (CIMs) which can be used to inform the policy making process. Going forward, over the longer term, reliable CIMs could form the basic foundation of a shift to an inflation targeting regime in Vietnam. To this end, the paper overviews the inflation process and identifies key determinants of inflation. The paper then uses a filtering approach to narrow down potential CIMs that satisfy certain empirically desirable criteria. The paper finds that commonly used exclusion-based measures (EBMs) do not perform well against statistical criteria for admissible CIMs; trimmed mean measures (TMMs) do better. However, even among TMMs, the same TMM may not be appropriate for all periods. Periods of high and variable inflation require larger trims, and conversely - "one trim does not fit all periods". EVIEWS and MATLAB programs which accompany the paper allow quick, timely replication of CIMs as new data become available, making them valuable monetary policy tools for the State Bank of Vietnam on an ongoing basis.

From a policy standpoint, the results of the paper imply that while EBMs may be useful indicators for communication purposes, they may not be good guides for policy actions. This may well be a result of Vietnam's particular experience with external shocks and the composition of the inflation index which is still weighted heavily towards food and fuel, but the result may well carry over to other countries with similar economic structures. From an analytical standpoint — and a policy formulation perspective - the results suggest that policymakers and advocates need to test CIMs on an ongoing basis to form a firmer basis for policy actions. These conclusions stand well with the analytical literature and policy making across countries. 
Table 4. Evaluation of Exclusion-based CIMs (12-month)—Sample: 1999-2014

\begin{tabular}{|c|c|c|c|c|c|c|c|c|c|}
\hline \multirow{2}{*}{\multicolumn{10}{|c|}{ Marques et. al. Conditions }} \\
\hline & & & & & & & & & \\
\hline \multicolumn{10}{|l|}{ Condition 1a. $(\mathrm{HI}-\mathrm{Cl})$ is a zero-mean stationary } \\
\hline t-stat & & -3.4 & -4.4 & -2.0 & -1.1 & -2.7 & -3.3 & -2.8 & -3.1 \\
\hline Prob (t-stat) & & 0.0 & 0.0 & 0.3 & 0.7 & 0.1 & 0.0 & 0.1 & 0.0 \\
\hline Null: unit root, not accepted means OK & & Yes** & Yes*** & No & No & Yes* & Yes** & Yes* & Yes** \\
\hline \multicolumn{10}{|l|}{ Condition 1b. Cointegration with unit coefficient } \\
\hline t-stat & & 0.8 & 0.9 & -0.2 & 0.5 & 1.3 & 0.8 & 1.4 & 2.1 \\
\hline Prob (t-stat) & & 0.4 & 0.3 & 0.8 & 0.6 & 0.2 & 0.4 & 0.2 & 0.0 \\
\hline Null: alpha $=0$ given beta $=1$, accepted means $\mathrm{OK}$ & & Yes*** & Yes*** & Yes*** & Yes*** & Yes*** & Yes*** & Yes*** & Yes* \\
\hline \multicolumn{10}{|l|}{ Condition 2. $\mathrm{Cl}$ is an attractor for $\mathrm{HI}$} \\
\hline t-stat & & -2.4 & -0.5 & 3.2 & 1.4 & -2.9 & -2.3 & -2.9 & -3.1 \\
\hline Prob (t-stat) & & 0.0 & 0.6 & 0.0 & 0.2 & 0.0 & 0.0 & 0.0 & 0.0 \\
\hline Null: gamma $=0$, not accepted means OK & & Yes** & No & Yes*** & No & Yes*** & Yes** & Yes*** & Yes*** \\
\hline \multicolumn{10}{|l|}{ Condition 3a. Weak exogeneity } \\
\hline t-stat & & 0.3 & -0.5 & -3.4 & -1.8 & 0.1 & 0.2 & 0.1 & 0.1 \\
\hline Prob (t-stat) & & 0.8 & 0.7 & 0.0 & 0.1 & 1.0 & 0.8 & 1.0 & 1.0 \\
\hline Null: lambda $=0$, accepted means OK & & Yes*** & Yes*** & No & Yes** & Yes*** & Yes*** & Yes*** & Yes*** \\
\hline \multicolumn{10}{|l|}{ Condition $3 b$. Strong exogeneity } \\
\hline F-stat (Wald test) & & 12.9 & 1.9 & 2.0 & 1.0 & 8.4 & 13.3 & 8.3 & 14.1 \\
\hline Prob (F-stat) & & 0.0 & 0.1 & 0.1 & 0.4 & 0.0 & 0.0 & 0.0 & 0.0 \\
\hline Null: thetas $=0$ given lambda $=0$, accepted means $O K$ & & No & Yes*** & Yes*** & Yes*** & No & No & No & No \\
\hline \multicolumn{10}{|l|}{ Volatility } \\
\hline Standard deviation & 6.5 & 4.7 & 6.6 & 6.8 & 7.2 & 4.5 & 4.8 & 4.5 & 4.7 \\
\hline Coefficient of variation & 0.9 & 0.7 & 0.9 & 0.9 & 1.0 & 0.7 & 0.7 & 0.7 & 0.8 \\
\hline \multicolumn{10}{|l|}{ Smoothness vis-as-vis MA12(CPI) } \\
\hline RMSD & 1.5 & 2.3 & 1.5 & 1.7 & 2.2 & 2.6 & 2.3 & 2.6 & 2.4 \\
\hline MAD & 1.0 & 1.9 & 1.1 & 1.2 & 1.5 & 2.1 & 1.9 & 2.1 & 2.0 \\
\hline \multicolumn{10}{|l|}{ Summary statistics } \\
\hline Mean & 7.4 & 6.7 & 7.3 & 7.5 & 7.3 & 6.4 & 6.7 & 6.3 & 6.0 \\
\hline Median & 6.8 & 6.3 & 6.7 & 6.7 & 5.8 & 6.1 & 6.2 & 6.0 & 5.6 \\
\hline Standard deviation & 6.5 & 4.7 & 6.6 & 6.8 & 7.2 & 4.5 & 4.8 & 4.5 & 4.7 \\
\hline Skewness & 1.2 & 0.9 & 1.2 & 1.3 & 1.4 & 0.8 & 1.0 & 0.8 & 1.1 \\
\hline Kurtosis & 4.5 & 3.5 & 4.5 & 4.7 & 4.9 & 3.2 & 3.8 & 3.2 & 4.0 \\
\hline
\end{tabular}

Source: Authors' calculations.

$1 /{ }^{* * *}$ significant at 1 percent level; ${ }^{* *}$ significant at 5 percent level; ${ }^{*}$ significant at 10 percent level.

2/Yes/No indicates whether a measure satisfies a criterion (along with Null hypothesis). 
Figure 3. 12-month TMMs: Marques et. al. "Attractor" Conditions-Sample: 1999-2014

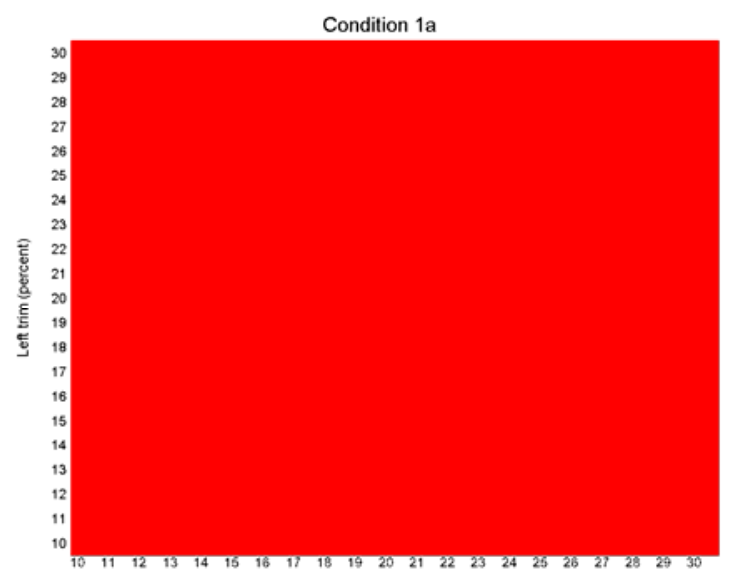

Right trim (percent)

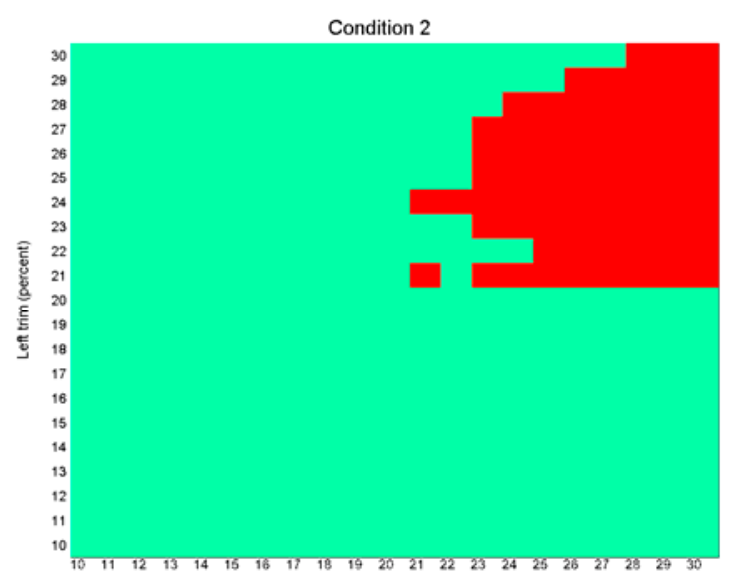

Right trim (percent)

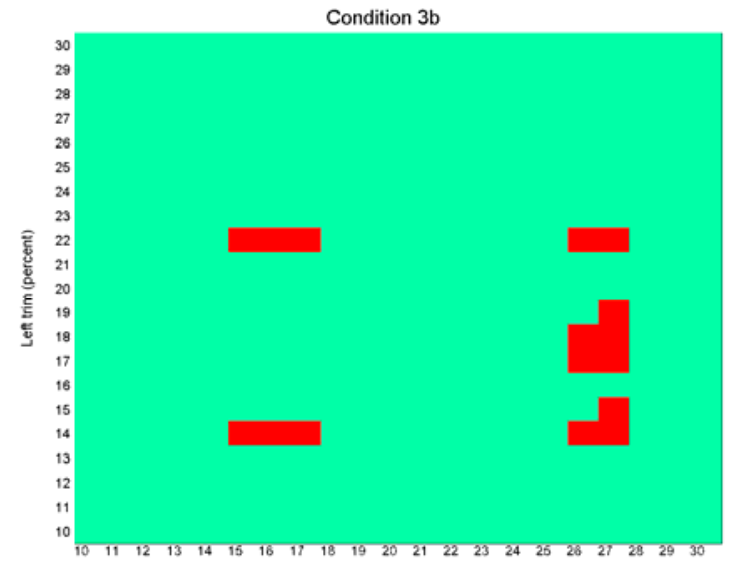

Right trim (percent)

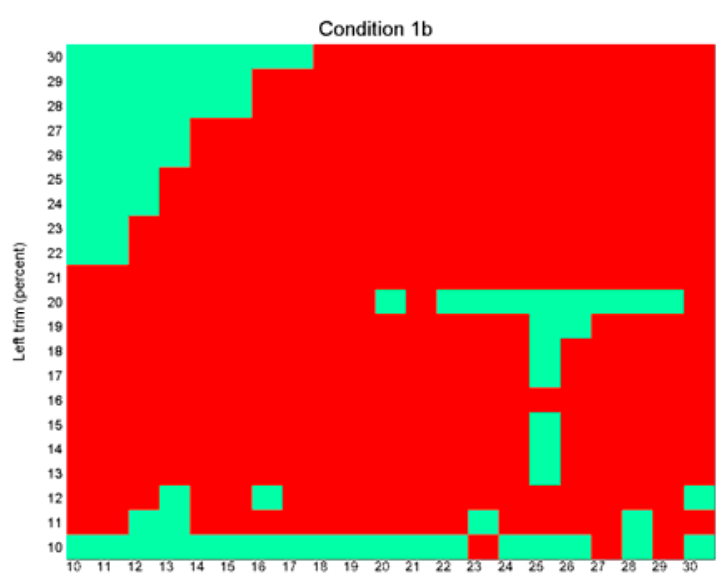

Right trim (percent)

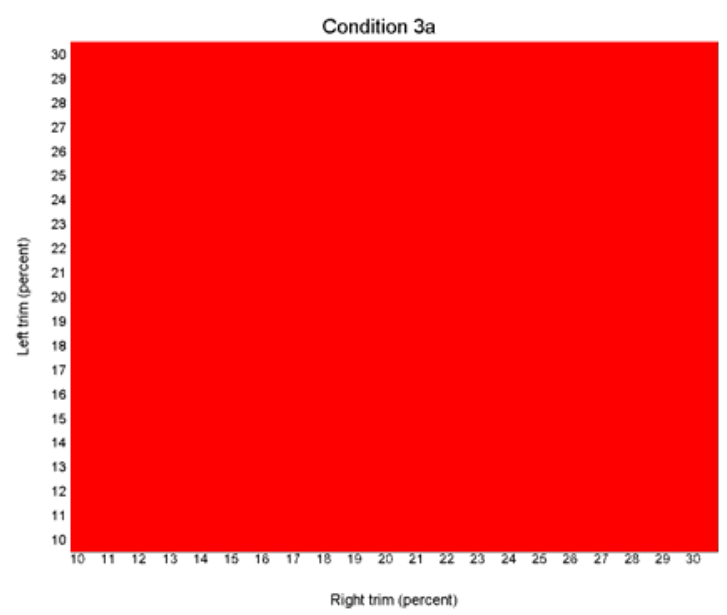

Marquez Conditions

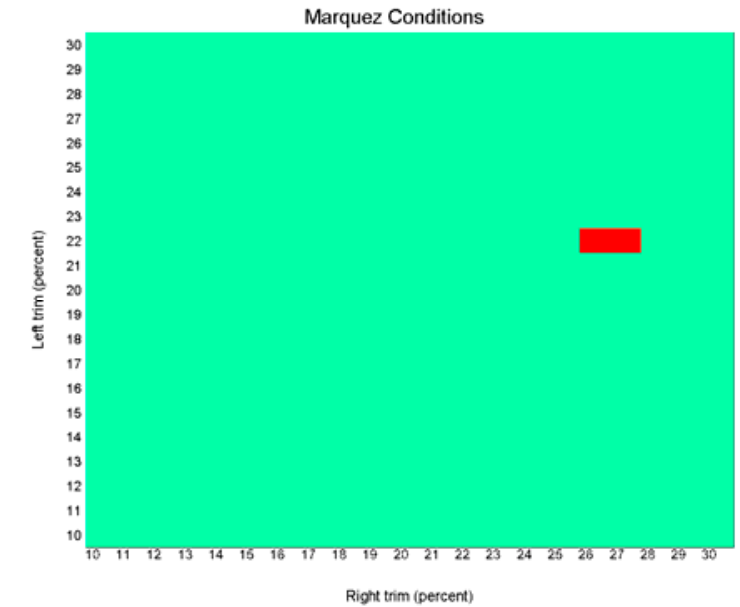

Source: Authors' calculations.

Note: Red means that the condition is satisfied. 
Figure 4. 12-month TMMs: Smoothness and Volatility—Sample: 1999-2014

Root Mean Standard Deviation

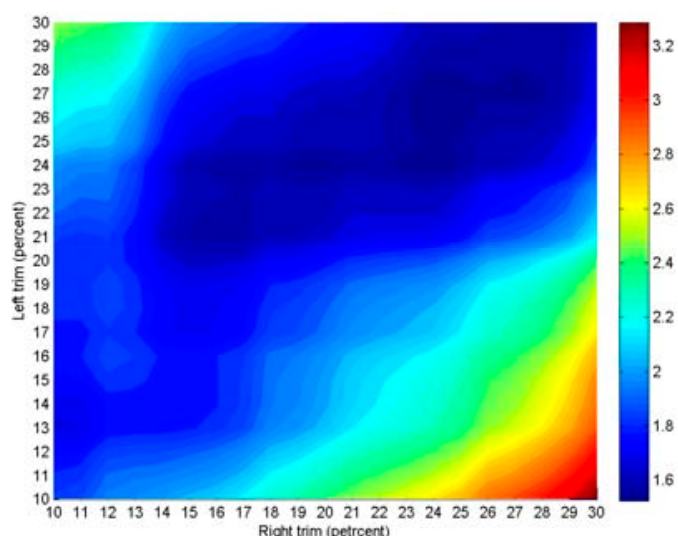

Standard Deviation

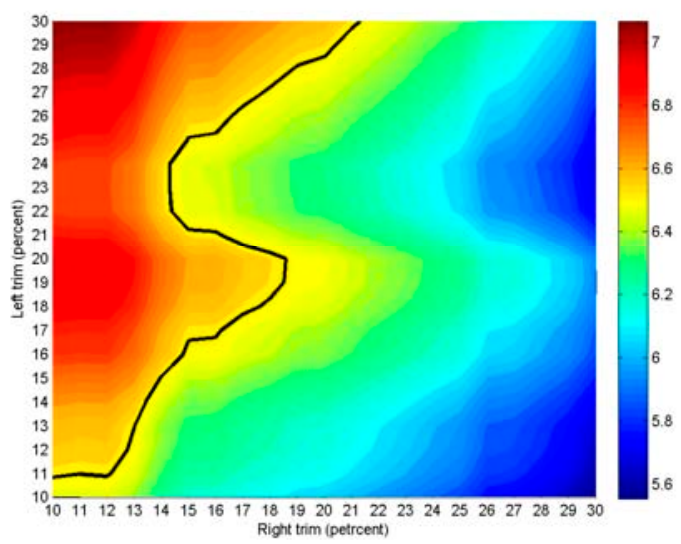

Mean Absolute Deviation

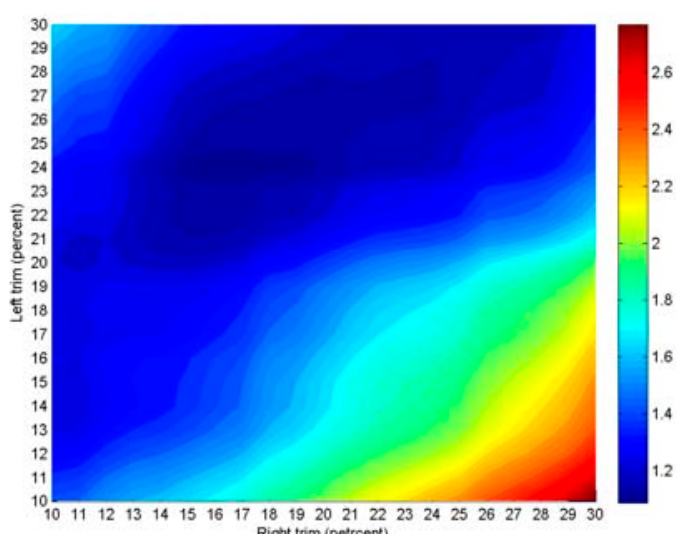

Coefficient of Variation

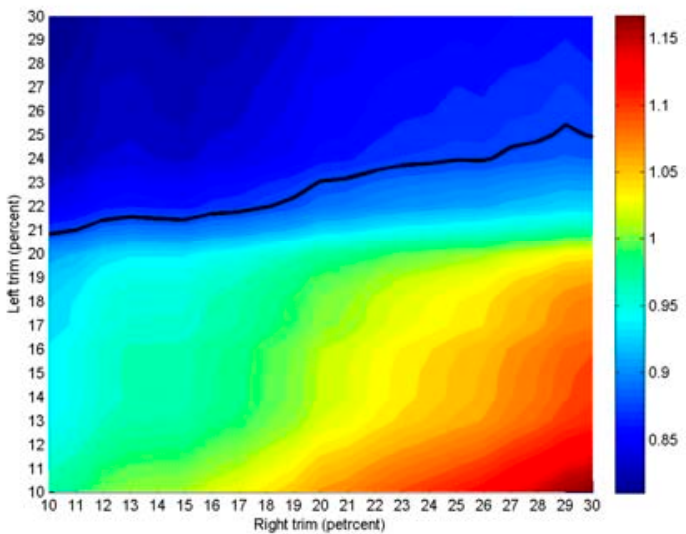

Source: Authors' calculations.

Note: The black contour lines are values for headline inflation. 
Table 5. Evaluation of Exclusion-based CIMs (12-month)—Sample: 1999-2007

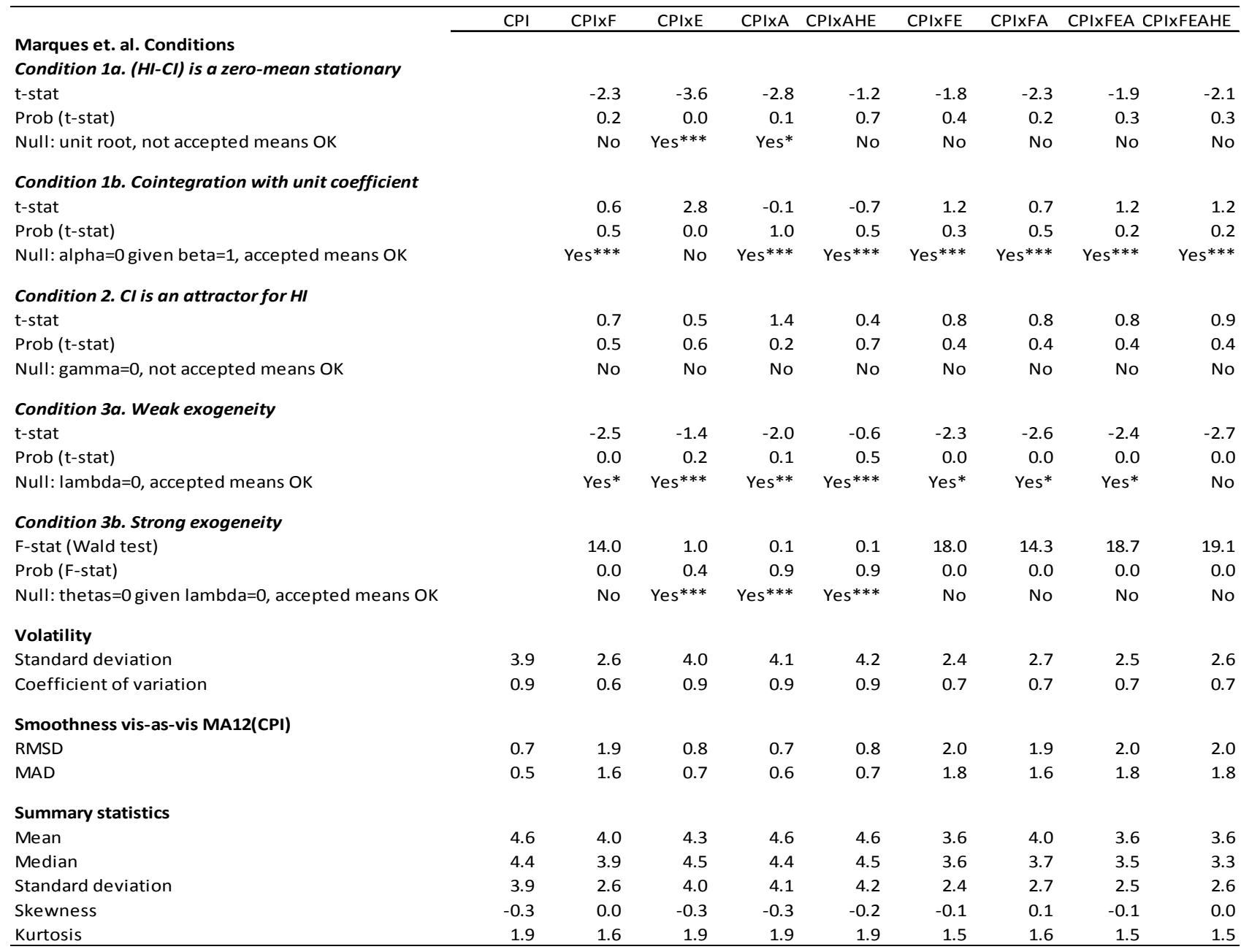

Source: Authors' calculations.

$1 /{ }^{* * *}$ significant at 1 percent level; ${ }^{* *}$ significant at 5 percent level; ${ }^{*}$ significant at 10 percent level.

2/ Yes/No indicates whether a measure satisfies a criterion (along with Null hypothesis). 
Figure 5. 12-month TMMs: Marques et. al. “Attractor” Conditions-Sample: 1999-2007

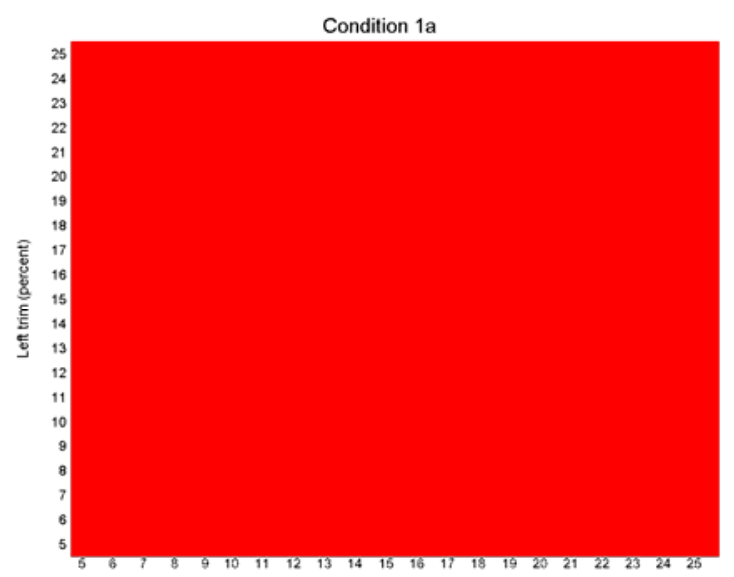

Right trim (percent)

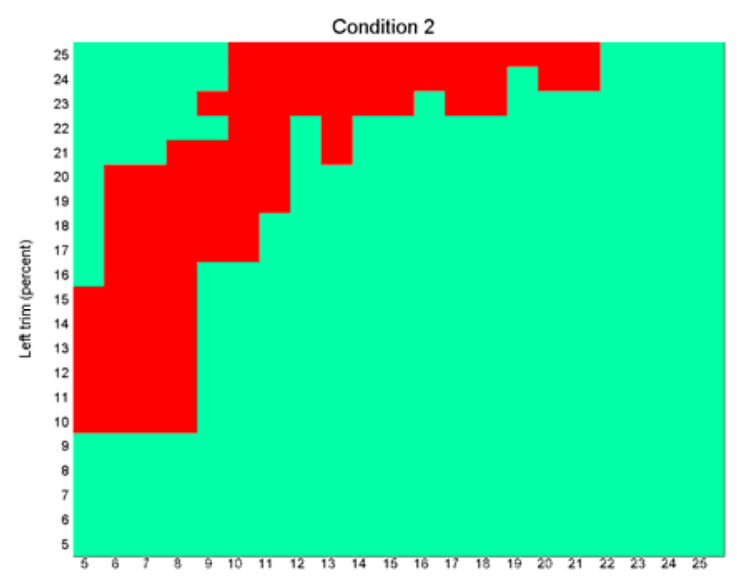

Right trim (percent)

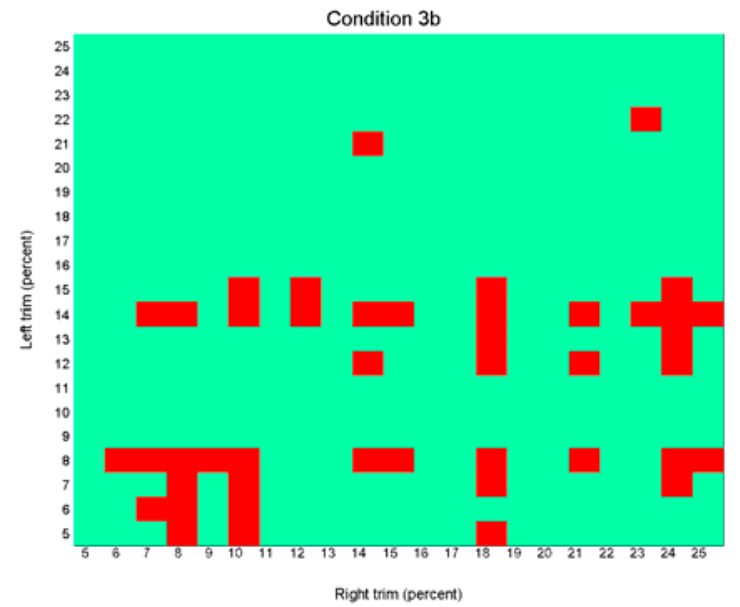

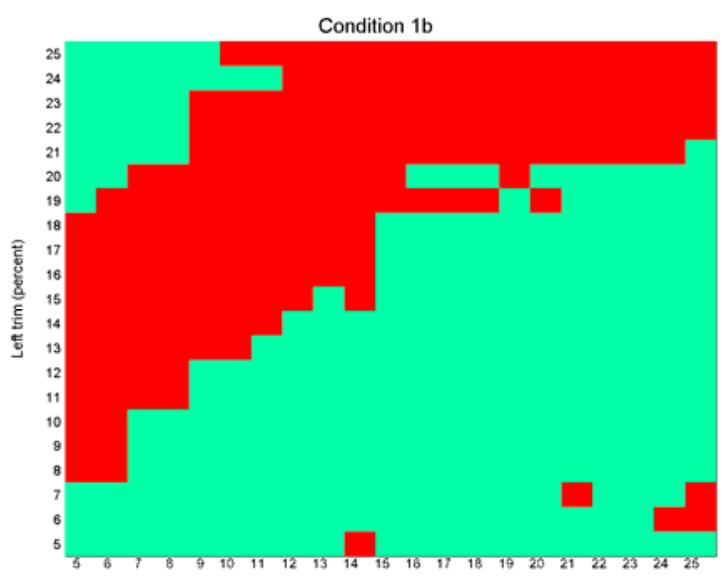

Right trim (percent)

Condition 3a

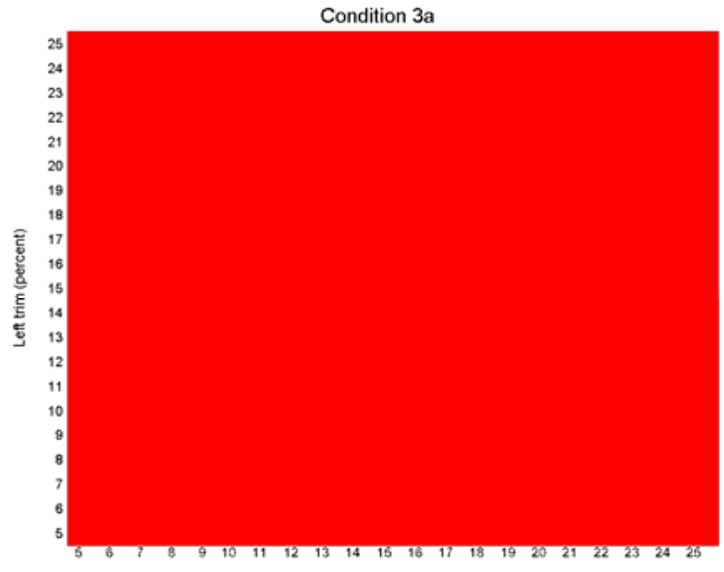

Right trim (percent)

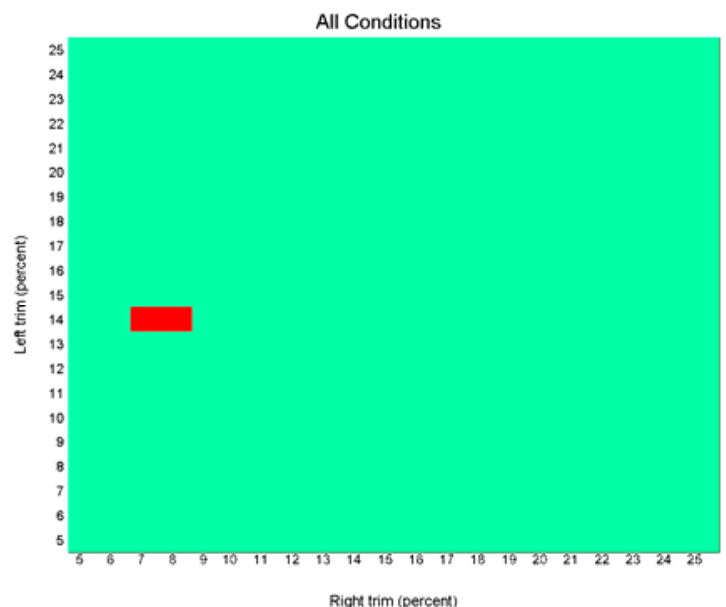

Source: Authors' calculations.

Note: Red means that the condition is satisfied. 
Figure 6. 12-month TMMs: Smoothness and Volatility-Sample: 1999-2007

Root Mean Standard Deviation

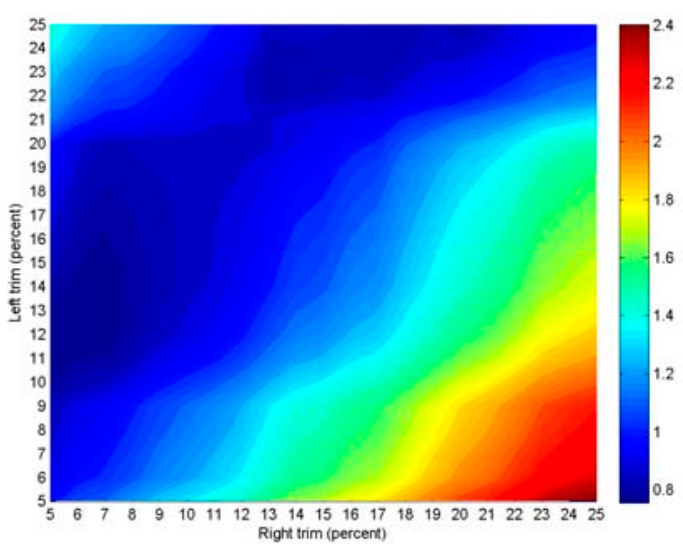

Standard Deviation

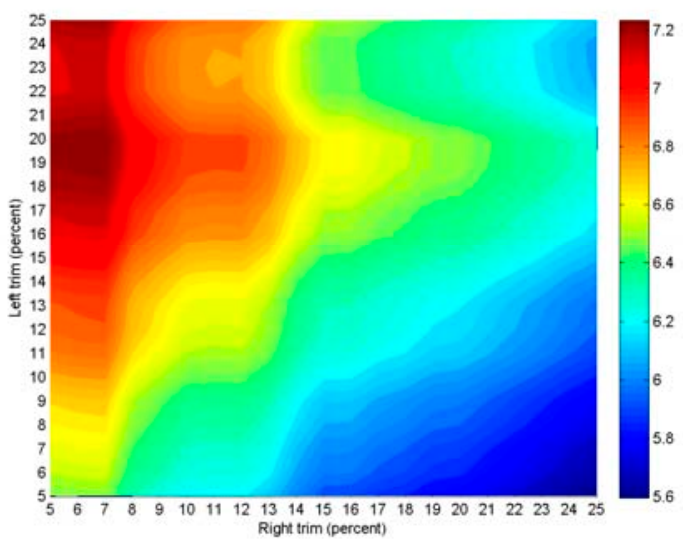

Mean Absolute Deviation

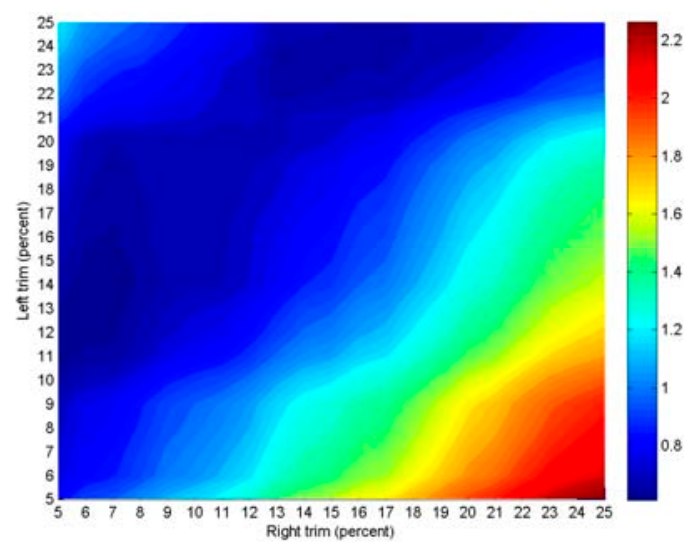

Coefficient of Variation

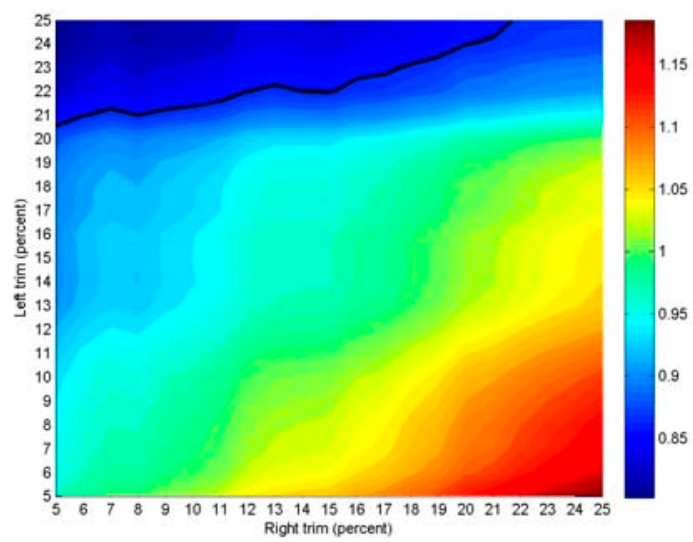

Source: Authors' calculations.

Note: The black contour lines are values for headline inflation. 
Table 6. Evaluation of Exclusion-based CIMs (12-month)—Sample: 2008-2014

\begin{tabular}{|c|c|c|c|c|c|c|c|c|c|}
\hline Marques et. al. Conditions & $\mathrm{CPI}$ & $\mathrm{CPIxF}$ & CPIXE & CPIxA & CPIXAHE & \multirow[t]{2}{*}{ CPIxFE } & \multirow[t]{2}{*}{ CPIxFA } & \multicolumn{2}{|c|}{ CPIXFEA CPIXFEAHE } \\
\hline \multicolumn{8}{|l|}{ Condition $1 \mathrm{a} .(\mathrm{HI}-\mathrm{Cl})$ is a zero-mean stationary } & & \\
\hline t-stat & & -2.3 & -3.2 & -1.9 & -2.5 & -2.5 & -2.2 & -2.5 & -2.7 \\
\hline Prob (t-stat) & & 0.2 & 0.0 & 0.4 & 0.1 & 0.1 & 0.2 & 0.1 & 0.1 \\
\hline Null: unit root, not accepted means OK & & No & Yes** & No & No & No & No & No & Yes* \\
\hline \multicolumn{10}{|l|}{ Condition 1b. Cointegration with unit coefficient } \\
\hline t-stat & & 0.3 & -0.1 & 0.3 & 1.1 & 0.3 & 0.4 & 0.3 & 1.1 \\
\hline Prob (t-stat) & & 0.8 & 0.9 & 0.7 & 0.3 & 0.8 & 0.7 & 0.8 & 0.3 \\
\hline Null: alpha $=0$ given beta $=1$, accepted means $O K$ & & Yes*** & Yes*** & Yes*** & Yes*** & Yes*** & Yes*** & Yes*** & Yes*** \\
\hline \multicolumn{10}{|l|}{ Condition 2. $\mathrm{Cl}$ is an attractor for $\mathrm{HI}$} \\
\hline t-stat & & -3.7 & -0.6 & 4.5 & 1.6 & -3.8 & -3.4 & -3.8 & -3.8 \\
\hline Prob (t-stat) & & 0.0 & 0.6 & 0.0 & 0.1 & 0.0 & 0.0 & 0.0 & 0.0 \\
\hline Null: gamma $=0$, not accepted means OK & & Yes*** & No & Yes*** & No & Yes*** & Yes*** & Yes*** & Yes*** \\
\hline \multicolumn{10}{|l|}{ Condition 3a. Weak exogeneity } \\
\hline t-stat & & 1.8 & -0.2 & -4.4 & -2.0 & 1.6 & 1.7 & 1.6 & 1.8 \\
\hline Prob (t-stat) & & 0.1 & 0.8 & 0.0 & 0.1 & 0.1 & 0.1 & 0.1 & 0.1 \\
\hline Null: lambda=0, accepted means OK & & Yes** & Yes*** & No & Yes* & Yes*** & Yes*** & Yes*** & Yes** \\
\hline \multicolumn{10}{|l|}{ Condition $3 b$. Strong exogeneity } \\
\hline F-stat (Wald test) & & 10.3 & 0.7 & 5.0 & 1.9 & 2.0 & 10.6 & 1.8 & 5.6 \\
\hline Prob (F-stat) & & 0.0 & 0.6 & 0.0 & 0.1 & 0.1 & 0.0 & 0.1 & 0.0 \\
\hline Null: thetas $=0$ given lambda $=0$, accepted means $\mathrm{OK}$ & & No & Yes*** & No & Yes*** & Yes*** & No & Yes*** & No \\
\hline \multicolumn{10}{|l|}{ Volatility } \\
\hline Standard deviation & 7.3 & 4.6 & 7.3 & 7.7 & 8.7 & 4.1 & 4.8 & 4.1 & 5.0 \\
\hline Coefficient of variation & 0.7 & 0.5 & 0.7 & 0.7 & 0.8 & 0.4 & 0.5 & 0.4 & 0.5 \\
\hline \multicolumn{10}{|l|}{ Smoothness vis-as-vis MA12(CPI) } \\
\hline RMSD & 2.0 & 2.2 & 1.9 & 2.3 & 3.1 & 2.4 & 2.1 & 2.4 & 2.3 \\
\hline MAD & 1.6 & 1.9 & 1.4 & 1.7 & 2.6 & 2.0 & 1.9 & 2.0 & 1.9 \\
\hline \multicolumn{10}{|l|}{ Summary statistics } \\
\hline Mean & 11.1 & 10.1 & 11.1 & 11.2 & 10.8 & 9.9 & 10.1 & 9.9 & 9.2 \\
\hline Median & 8.3 & 9.4 & 7.5 & 8.0 & 8.3 & 9.4 & 9.4 & 9.4 & 7.7 \\
\hline Standard deviation & 7.3 & 4.6 & 7.3 & 7.7 & 8.7 & 4.1 & 4.8 & 4.1 & 5.0 \\
\hline Skewness & 0.9 & 0.5 & 0.9 & 0.9 & 0.9 & 0.5 & 0.6 & 0.5 & 0.7 \\
\hline Kurtosis & 2.5 & 2.5 & 2.6 & 2.7 & 2.6 & 2.4 & 2.7 & 2.4 & 2.4 \\
\hline
\end{tabular}

Source: Authors' calculations.

$1 /{ }^{* * *}$ significant at 1 percent level; ${ }^{* *}$ significant at 5 percent level; ${ }^{*}$ significant at 10 percent level. 
Figure 7. 12-month TMMs: Marques et. al. “Attractor" Conditions-Sample: 2008-2014

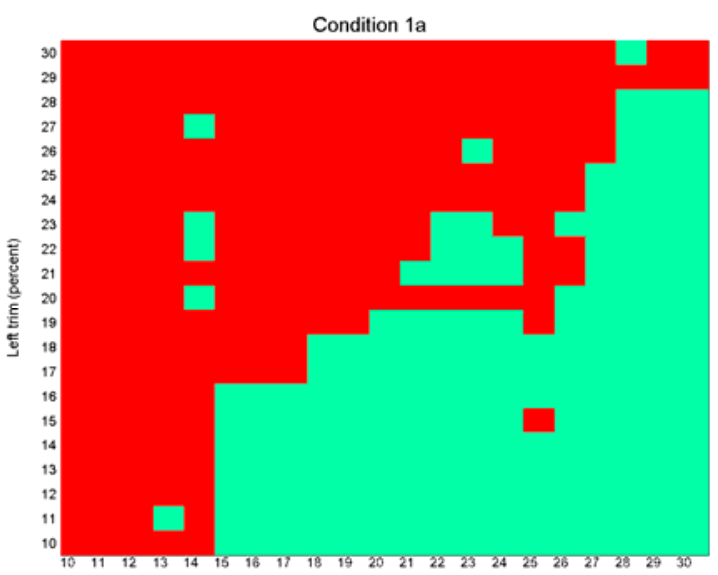

Right trim (percent)

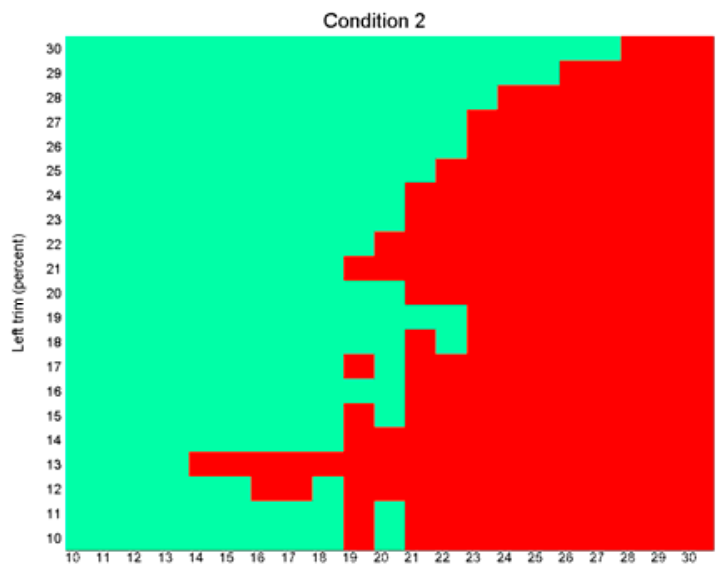

Right trim (percent)

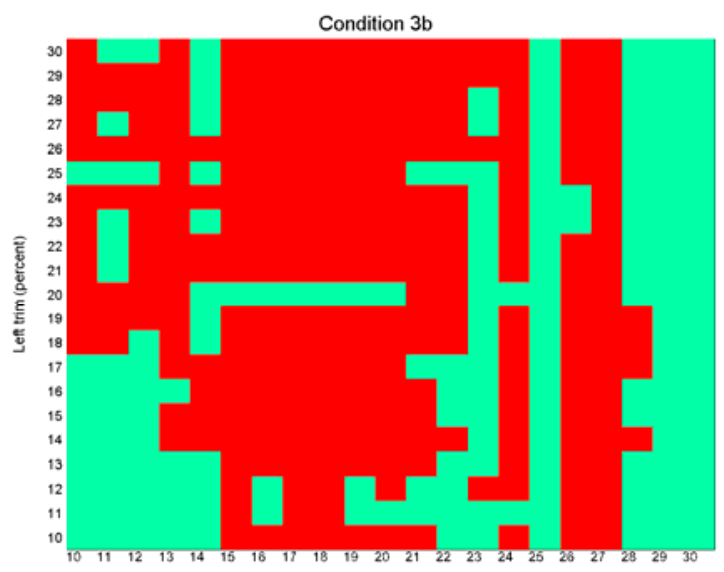

Right trim (percent)

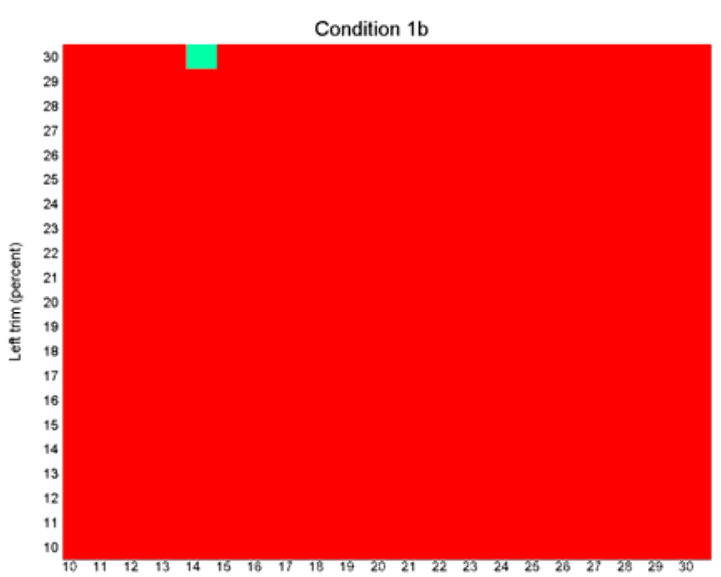

Right trim (percent)

Condition 3a

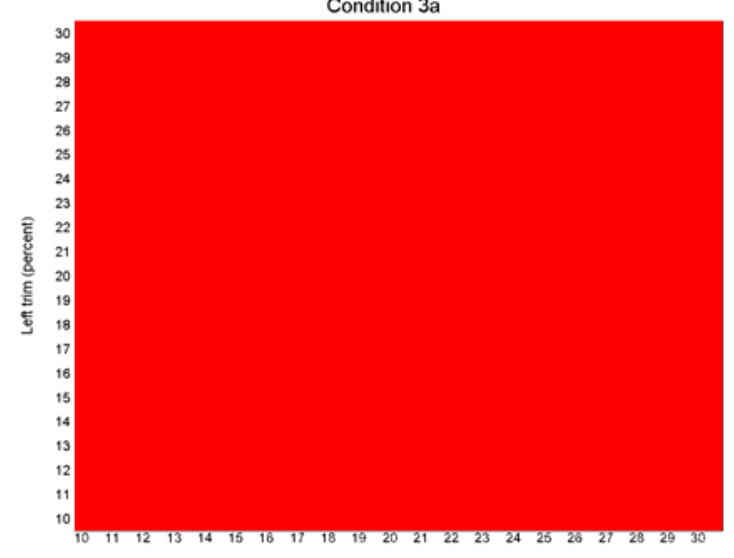

Right trim (percent)

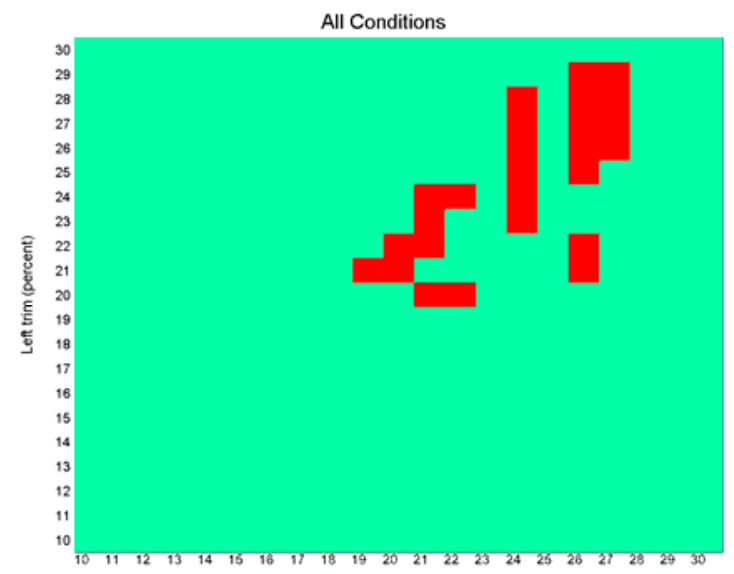

Right trim (percent)

Source: Authors' calculations.

Note: Red means that the condition is satisfied. 
Figure 8. 12-month TMMs: Smoothness and Volatility—Sample: 2008-2014

Root Mean Standard Deviation

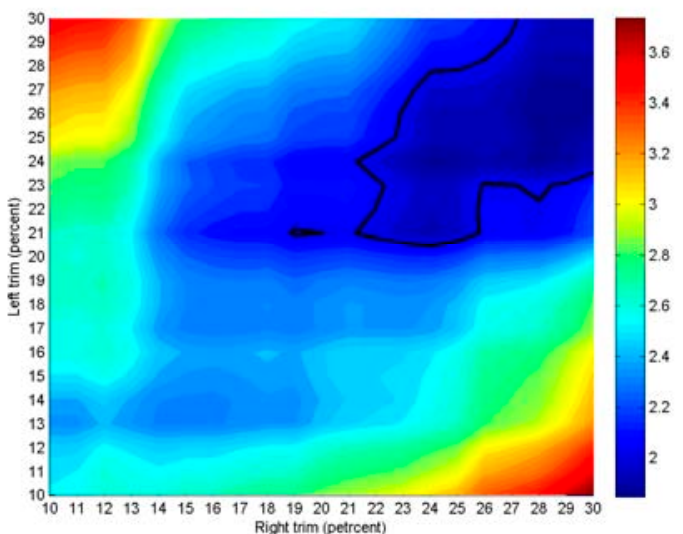

Standard Deviation

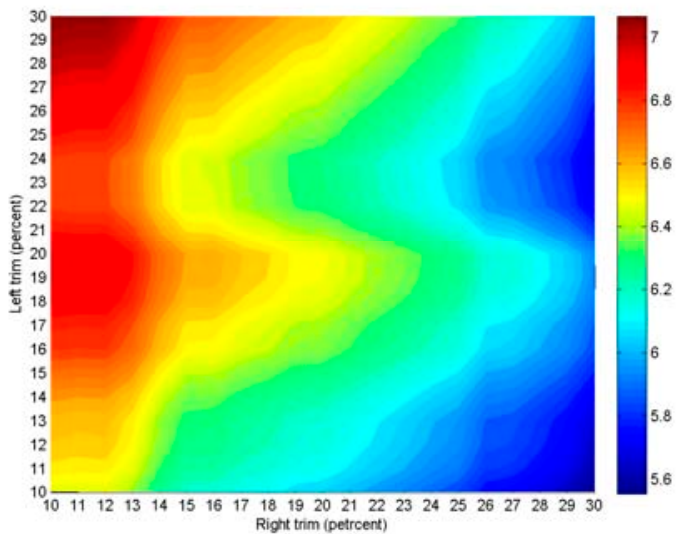

Mean Absolute Deviation

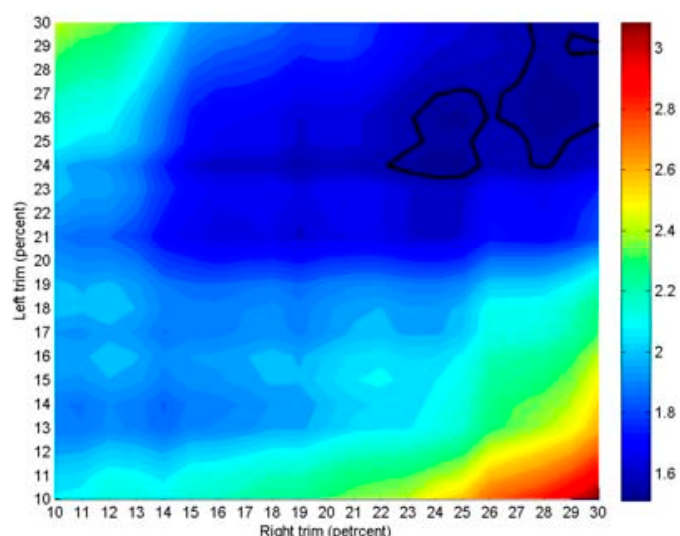

Coefficient of Variation

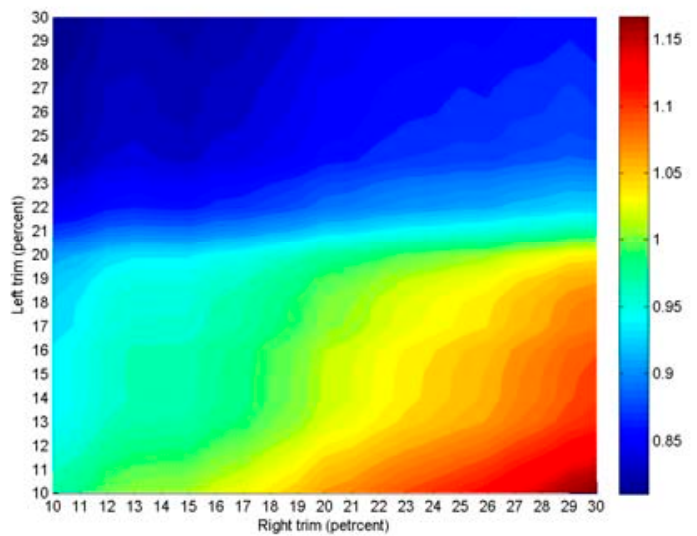

Source: Authors' calculations.

Note: The black contour lines are values for headline inflation. 
Figure 9. Cogley Tests for TMM $\beta$ s
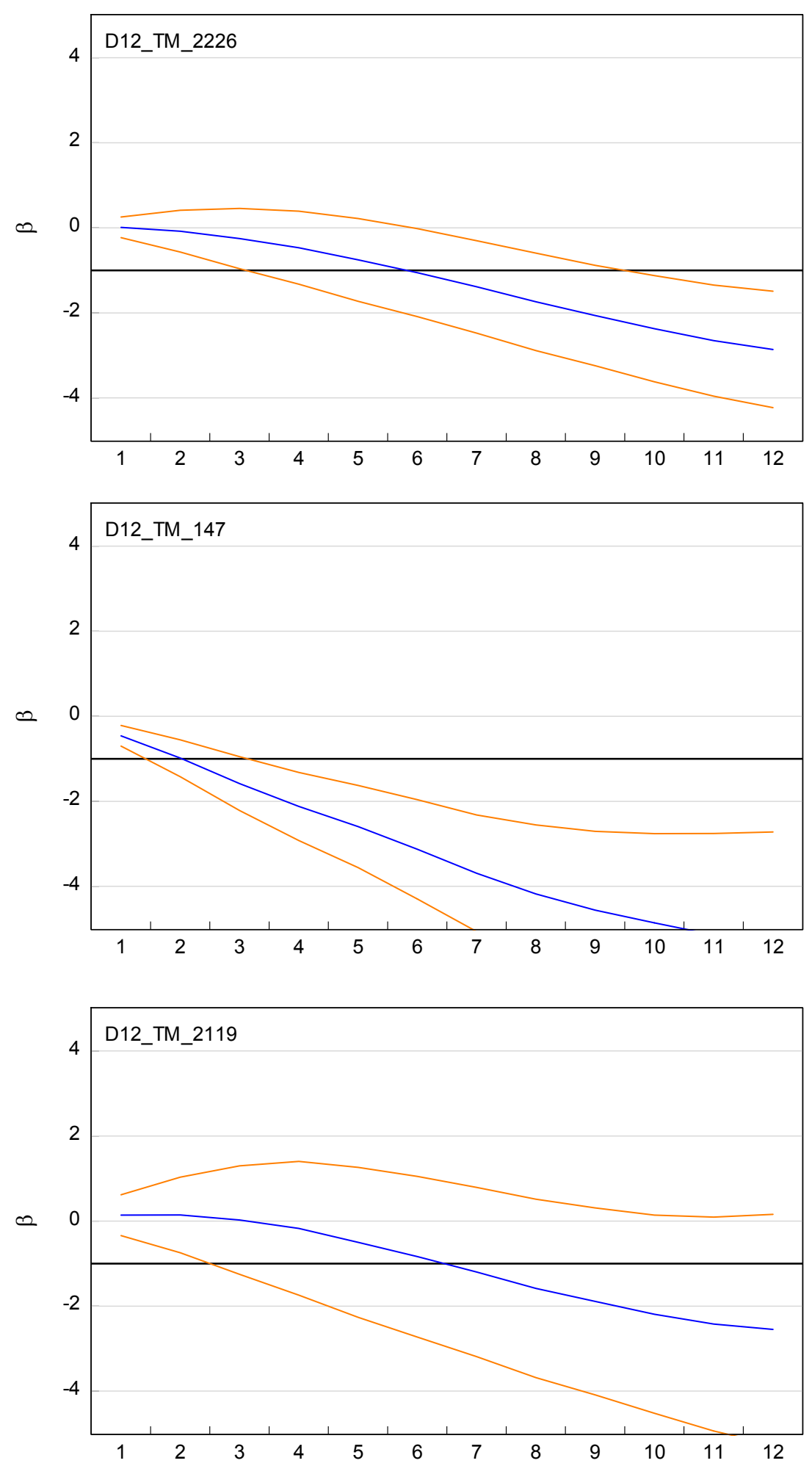

Source: Authors' calculations, confidence interval at 95 percent significance 
Table 7. Cogley Test Wald F-statistics

(Null Hypothesis: $\alpha=0$ and $\beta=-1$ )

\begin{tabular}{cccc}
\hline & \multicolumn{3}{c}{ Sample/TMM } \\
\cline { 2 - 4 } Horizon & 1999-2014 & $\begin{array}{c}\text { 1999-2007 } \\
\text { TMM147 }\end{array}$ & $\begin{array}{c}\text { 2008-14 } \\
\text { TMM2119 }\end{array}$ \\
\hline 1 & 0.00 & 0.00 & 0.00 \\
2 & 0.00 & 0.39 & 0.05 \\
3 & 0.07 & 0.17 & 0.28 \\
4 & 0.31 & 0.03 & 0.52 \\
5 & 0.54 & 0.01 & 0.72 \\
6 & 0.54 & 0.00 & 0.80 \\
7 & 0.37 & 0.00 & 0.74 \\
8 & 0.20 & 0.00 & 0.58 \\
9 & 0.11 & 0.00 & 0.41 \\
10 & 0.06 & 0.00 & 0.27 \\
11 & 0.04 & 0.00 & 0.19 \\
12 & 0.03 & 0.01 & 0.16 \\
\hline
\end{tabular}

Source: Authors' calculations. 
Figure 10. Headline Inflation, EBMs and TMMs
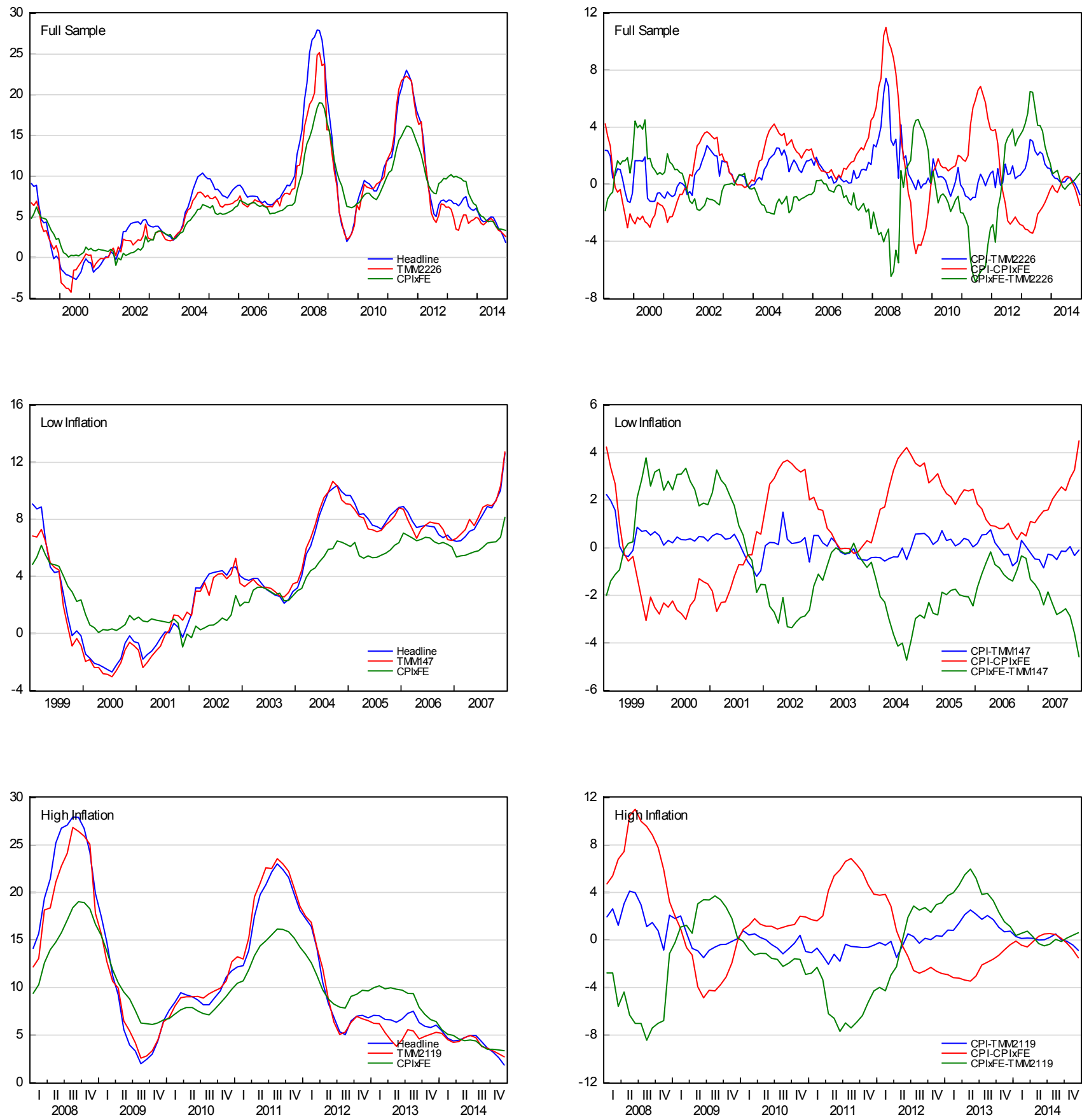

Source: Authors' calculations. 


\section{References}

Bryan, Michael F. and Cecchetti, Stephen G. "Inflation and the distribution of price changes." The Review of Economics and Statistics 81, no. 2 (May 1999): 188-196.

Bryan, Michael; Cecchetti, Stephen G. and Wiggins II, Rodney L. "Efficient Inflation Estimation." NBER Working Paper 6183 (1997).

Cogley, Timothy. "A simple adaptive measure of core inflation." Journal of Money, Credit and Banking 34, no. 1 (Febuary 2002): 94-113.

Eckstein, O. Core inflation. Englewood Cliffs, N.J.: Prentice-Hall, 1981.

Flemming, J. Inflation. London: Oxford University Press, 1976.

Ginting, Edimon. "Is inflation in India an attractor of inflation in Nepal." IMF Working Paper, no. WP/07/269 (2007).

Lai, Ngoc-Anh. "Which core inflation measures for Vietnam?" A part of Ph.D thesis at Universite Paris I Patheon-Sorbonne, August 2013.

Marques, Carlos Robalo and Joao Machado Mota. "Using the assymmetric trimmed mean as a core inflation indicator." Economic Bullentin, Banco de Protugal, September 2000: $85-95$.

Marques, Carlos Robalo, Pedro Duarte Neves, Luis Morais Sarmento. "Evaluating core inflation indicators." Economic Modelling 20 (2003): 765-75.

Nguyen, Huu Minh; Cavoli, Tony and Wilson, John K. "The Determinants of Inflation in Vietnam, 2001-09." ASEAN Economic Bulletin 29, no. 1 (2012): 1-14.

Okun, A. "Inflation: the problems and prospects before us." In Inflation: the problems it creates and the policies it requries, by A Okun, M Gilbert, H Fowler, 3-53. New York: New York University press, 1970.

Quah, Danny and Shaun P. Vahey. "Measuring Core Inflation." The Economic Journal 105, no. 432 (September 1995): 1130 - 1144.

Roger, Scott. "Core Inflation: concepts, uses and measurement." Reserve Bank of New Zealand Discussion paper G98/9 (1998).

Roger, Scott. "Vietnam core inflation measuremnet and forecasting issues." International Monetary Fund, January 2008.

Silver, Mick. "Core inflation measures and statistical issues in choosing among them." IMF Working paper WP/06/97 (2006).

Wynne, Mark A. "Core Inflation: A review of some conceptual issues." Federal Reserve Bank of St. Louis Review 90, no. 3, Part 2 (May/June 2008): 205-28. 